\title{
Clinical characteristics, laboratory abnormalities and CT findings of COVID-19 patients and risk factors of severe disease: a systematic review and meta-analysis
}

\author{
Jingyuan Xie ${ }^{1 \#}$, Qin Wang ${ }^{1 \#}$, Yangyang Xu' ${ }^{2}$, Tianli Zhang ${ }^{3}$, Lu Chen ${ }^{1}$, Xueying Zuo ${ }^{1}$, Jiaxin Liu ${ }^{1}$, \\ Litang Huang ${ }^{3}$, Ping Zhan ${ }^{1,2,3}$, Tangfeng Lv ${ }^{1,2,3}$, Yong Song ${ }^{1,2,3}$ \\ ${ }^{1}$ Department of Respiratory and Critical Care Medicine, Jinling Hospital, Medical School of Nanjing University, Nanjing, China; ${ }^{2}$ Department of \\ Respiratory and Critical Care Medicine, Jinling Hospital, Jinling Clinical College of Nanjing Medical University, Nanjing, China; ${ }^{3}$ Department of \\ Respiratory and Critical Care Medicine, Jinling Hospital, Medical School of Southeast University, Nanjing, China \\ Contributions: (I) Conception and design: P Zhan, T Lv, Q Wang; (II) Administrative support: T Lv, Y Song, Q Wang; (III) Provision of study \\ materials or patients: L Huang, J Liu, L Chen, X Zuo; (IV) Collection and assembly of data: J Xie, T Zhang, P Zhan; (V) Data analysis and \\ interpretation: J Xie, Y Xu, P Zhan; (VI) Manuscript writing: All authors; (VII) Final approval of manuscript: All authors. \\ \#These authors contributed equally to this work. \\ Correspondence to: Ping Zhan. Department of Respiratory and Critical Care Medicine, Jinling Hospital, Nanjing University School of Medicine, 305 \\ East Zhongshan Road, Nanjing 210002, China. Email: zhanping207@163.com; Tangfeng Lv. Department of Respiratory and Critical Care Medicine, \\ Jinling Hospital, Nanjing University School of Medicine, 305 East Zhongshan Road, Nanjing 210002, China. Email: bairoushui@163.com; Yong \\ Song. Department of Respiratory and Critical Care Medicine, Jinling Hospital, Nanjing University School of Medicine, 305 East Zhongshan Road, \\ Nanjing 210002, China. Email: yong_song6310@yahoo.com.
}

Background: The coronavirus disease 2019 (COVID-19) is an emerging pandemic of global public health concern. We aimed to summarize the characteristics of COVID-19 patients in the early stage of the pandemic and explore the risk factors of disease progression.

Methods: We conducted a systematic review with meta-analysis, searching three databases for studies published between January 1, 2020, and March 18, 2020. We used random-effects models to calculate the $95 \%$ confidence intervals of pooled estimated prevalence and the odds ratio between the severe and nonsevere cases.

Results: Ninety studies involving 16,526 COVID-19 patients were included. Hypertension (19.1\%) and diabetes $(9.5 \%)$ were the most common comorbidities. The most prevalent clinical symptoms were fever (78.4\%), cough $(58.5 \%)$, and fatigue (26.4\%). Increased serum ferritin (74.2\%), high C-reactive protein $(73.3 \%)$, and high erythrocyte sedimentation rate (ESR) $(72.2 \%)$ were the most frequently reported laboratory abnormalities. Most patients had bilateral lung involvement (82.2\%) and showed peripheral $(66.9 \%)$ and subpleural (62.1\%) distribution, with multifocal involvement (73.1\%). And the most common CT features were vascular enlargement (64.3\%), ground-glass opacity (GGO) (60.7\%), and thickened interlobular septa (55.1\%). Respiratory failure was the most common complication $(30.7 \%)$ and the overall case-fatality rate (CFR) was $4.2 \%$. Moreover, male, history of smoking, and comorbidities might influence the prognosis. Most clinical symptoms such as fever, high fever, cough, sputum production, fatigue, shortness of breath, dyspnoea, and abdominal pain were linked to the severity of disease. Some specific laboratory indicators implied the deterioration of disease, such as leucocytosis, lymphopenia, platelet, alanine aminotransferase (ALT), aspartate aminotransferase (AST), albumin, creatinine, creatine kinase (CK), lactic dehydrogenase (LDH), C-reactive protein, procalcitonin (PCT), and D-dimer. Besides, the risk of bilateral pneumonia, consolidation, pleural effusion, and enlarged mediastinal nodes was higher in severe cases.

Conclusions: Most COVID-19 patients have fever and cough with lymphopenia and increased inflammatory indices, and the main CT feature is GGO involved bilateral lung. Patients with comorbidities and worse clinical symptoms, laboratory characteristics, and CT findings tend to have poor disease progression. 
Keywords: Coronavirus disease 2019 (COVID-19); clinical characteristics; laboratory abnormalities; CT findings; risk factors

Submitted Sep 17, 2020. Accepted for publication Nov 04, 2020.

doi: 10.21037/apm-20-1863

View this article at: http://dx.doi.org/10.21037/apm-20-1863

\section{Introduction}

In late December 2019, the coronavirus disease 2019 (COVID-19) caused by severe acute respiratory syndrome CoV-2 (SARS-CoV-2), has become an emerging pandemic of global public health concern (1). Then, the number of confirmed cases has exploded. As of March 30, 2020, almost 690 thousand confirmed patients have been reported with over 30 thousand deaths worldwide (2).

In 2003 and 2012, severe acute respiratory syndrome coronavirus (SARS-CoV) and Middle East respiratory syndrome coronavirus (MERS-CoV) caused epidemics respectively. According to the prior studies, the SARS$\mathrm{CoV}-2$, a betacoronavirus, is both similar and different to the SARS-CoV and MERS-CoV (3). As reported, the mortality of SARS-CoV and MERS-CoV is higher than that of SARS-CoV-2. But the pandemic caused by COVID-19 has exceeded the previous two diseases (4).

It is important to find out the epidemiological, clinical, laboratory and image features of patients with SARS$\mathrm{CoV}-2$ infection and risk factors of severe illness for better prevention and treatment of this disease. Large quantities of researches have made effort to understand this subject, but most were case series, cross-sectional studies, and case reports which were conducted in a particular hospital or area (5-20). Because of different study designs, small samples, and incomplete information, the characteristics and risk factors of COVID-19 are still unclear.

Some systematic reviews and meta-analyses have been already published, they summarized the clinical, laboratory and chest CT findings of COVID-19 patients $(21,22)$. However, they included a relatively small number of studies which were limited to China. In addition, few meta-analyses studied the risk factors related to poor outcomes owing to the lack of prognostic information in early studies. In this review, we summarized the prevalence of comorbidities, clinical symptoms, laboratory characteristics, chest CT findings, and complications of patients with SARS-CoV-2 infection in the early stage of the pandemic. Moreover, we analyzed the features of severe cases and non-severe cases and identified the risk factors of disease progression to offer clinicians references for clinical application and follow-up studies. We presented the following article in accordance with the PRISMA reporting checklist (available at http:// dx.doi.org/10.21037/apm-20-1863).

\section{Methods}

\section{Search strategy and selection criteria}

Our systematic review was in accordance with the Preferred Reporting Items for Systematic Reviews and Meta-Analyses (PRISMA) statement (23). We searched three databases, PubMed, Chinese medical journal network, and CNKI (China national knowledge infrastructure) to select relevant studies reporting COVID-19 which were published between Jan 1, 2020, and Mar 18, 2020. We used the following search terms: "COVID-19" or "Novel coronavirus" or "Novel coronavirus 2019" or "2019 nCoV" or "SARS$\mathrm{CoV}-2$ ". In order to ensure the comprehensiveness and accuracy of our study, we also reviewed the references of each included article.

We included studies that reported more than 50 cases of SARS-CoV-2 infection confirmed by real-time reverse transcriptase-polymerase chain reaction (RT-PCR) with demographical, clinical, laboratory, and image characteristics. Study type limit was not set, and we applied no language restrictions. We excluded the studies that only reported the infection in children, the elderly, or asymptomatic patients and the studies that lacked complete information or clear diagnostic criteria, as well as study sample was smaller than 50. Duplicate reports, review articles, commentary articles, and opinion articles were also excluded.

\section{Data extraction and quality assessment}

Three independent researchers (JX, TZ, YX) conducted data extraction and evaluated the literature quality. Any disagreement was resolved by another researcher (PZ). We collected the following variables from each included 
study: first author, the publishing institution, publication time, area, number of patients with COVID-19, median or mean age, sex ratio, smoking history, comorbidities, clinical symptoms, laboratory characteristics, image features, complications, and clinical outcome. All the outcomes of laboratory testing and chest CT we extracted were at the time of admission. We also extracted information of nonsevere and severe patients respectively. When the authors had no diagnostic criteria for severe illness, patients in the intensive care unit (ICU) were classified as severe cases. In the whole meta-analysis of pooled estimated prevalence, we excluded studies that only provided information of severe cases or non-severe cases, but included them in the metaanalysis that was limited to severe cases or non-severe cases, respectively. We used the MINORS to assess bias risk (24).

\section{Statistical analysis of data}

For pooled estimated prevalence, State software version 15.0 was used to analyze the data we extracted. We used random-effects models to calculate $95 \%$ confidence intervals (95\% CI) of pooled estimated prevalence (sex ratio, smoking history, comorbidities, clinical symptoms, laboratory characteristics, image features, and complications of COVID-19 patients). If the included article had a prevalence of $0 \%$ or $100 \%$, it would affect the accuracy of overall estimates. As reported, the Freeman-Tukey double arcsine transformation might minimize the effect, so we used this transformation to stabilize the variance before analysis (25). For calculating the odds ratio (OR), randomeffects models were used by Review Manager software version 5.3 due to the heterogeneity between the studies. Besides, the $\mathrm{I}^{2}$ statistic and Cochran's Q test were used to evaluate the degree of heterogeneity. Because most confirmed COVID-19 cases in China occurred in Wuhan and the Chinese government adopted different epidemic prevention measures in Wuhan and other cities, we conducted a subgroup analysis by city groups (Wuhan or other cities) to explore the possible source of heterogeneity and find out whether the prevalence of outcomes differed by different areas. $\mathrm{P}<0.05$ was considered to be statistically significant. Besides, we evaluated publication bias by Begg's test.

\section{Results}

\section{Study selection and quality assessment}

We searched 4,219 papers from the online databases by the above search strategy. A total of 3,712 papers were retained after the deletion of duplicate papers. By reading the titles and abstracts, 3,461 papers were excluded. Then, we assessed the full texts of the remaining 251 articles, of which 124 had a sample size less than 50,5 did not report clear diagnostic criteria, 3 only focused on infection in children, the elderly, or asymptomatic patients, and 29 did not report complete information or original data. Finally, we included 90 papers in our meta-analysis (Figure 1). We divided them into 4 parts, part 1 (5-20), part 2 (26-50), part 3 (51-75), part 4 (76-99). Among the included studies, five studies only provided information of severe cases and two studies only provided information of non-severe cases, which were excluded from the whole metaanalysis but were included in the meta-analysis limited to severe cases and non-severe cases, respectively. In addition, 28 studies provided information on both severe and non-severe patients and we included them in the meta-analysis to identify the risk factors of disease progression.

Table 1 lists the baseline characteristics of the included studies. All of the included studies were published between Jan 30, 2020, and Mar 18, 2020, in a sample size ranging from 50 to 1,590 patients. Among the included 90 studies with a total of 16,526 patients, 88 (97.8\%) were from China, of which 37 (41.1\%) were from Wuhan. Mean or median age of patients ranged from 37 to 68 years (median 48.8 years; 74 studies). Moreover, the proportion of severe cases ranged from $0.0 \%$ to $100.0 \%$ (median $23.1 \%$; 65 studies).

Table S1 lists the bias risk assessment of the included studies. Overall, according to the MINORS, all the included studies were rated fair for quality. The scores of these 90 studies ranged from 9 to 14 .

\section{Demographical characteristics and comorbidities}

The proportion of men in the 77 studies was $53.1 \%$ (95\% CI, 41.3-55.0\%). Moreover, the proportion of patients who had a history of smoking was $10.2 \%$ (95\% CI, 7.1-13.4\%). $32.5 \%$ of the patients had comorbidities (95\% CI, 29.0$36.1 \%$ ), and the most common were hypertension $(19.1 \%$, 95\% CI, 16.4-21.8\%), diabetes (9.5\%, 95\% CI, 8.1-10.8\%), and cardiovascular disease $(5.4 \%, 95 \% \mathrm{CI}, 4.2-6.7 \%)$ (Figure 2).

\section{Clinical symptoms and laboratory characteristics}

We analyzed the prevalence of 22 clinical symptoms. In which, the most prevalent were fever $(78.4 \%, 95 \%$ CI, $74.5-82.3 \%)$, cough $(58.5 \%, 95 \%$ CI, $51.4-65.6 \%)$, fatigue 


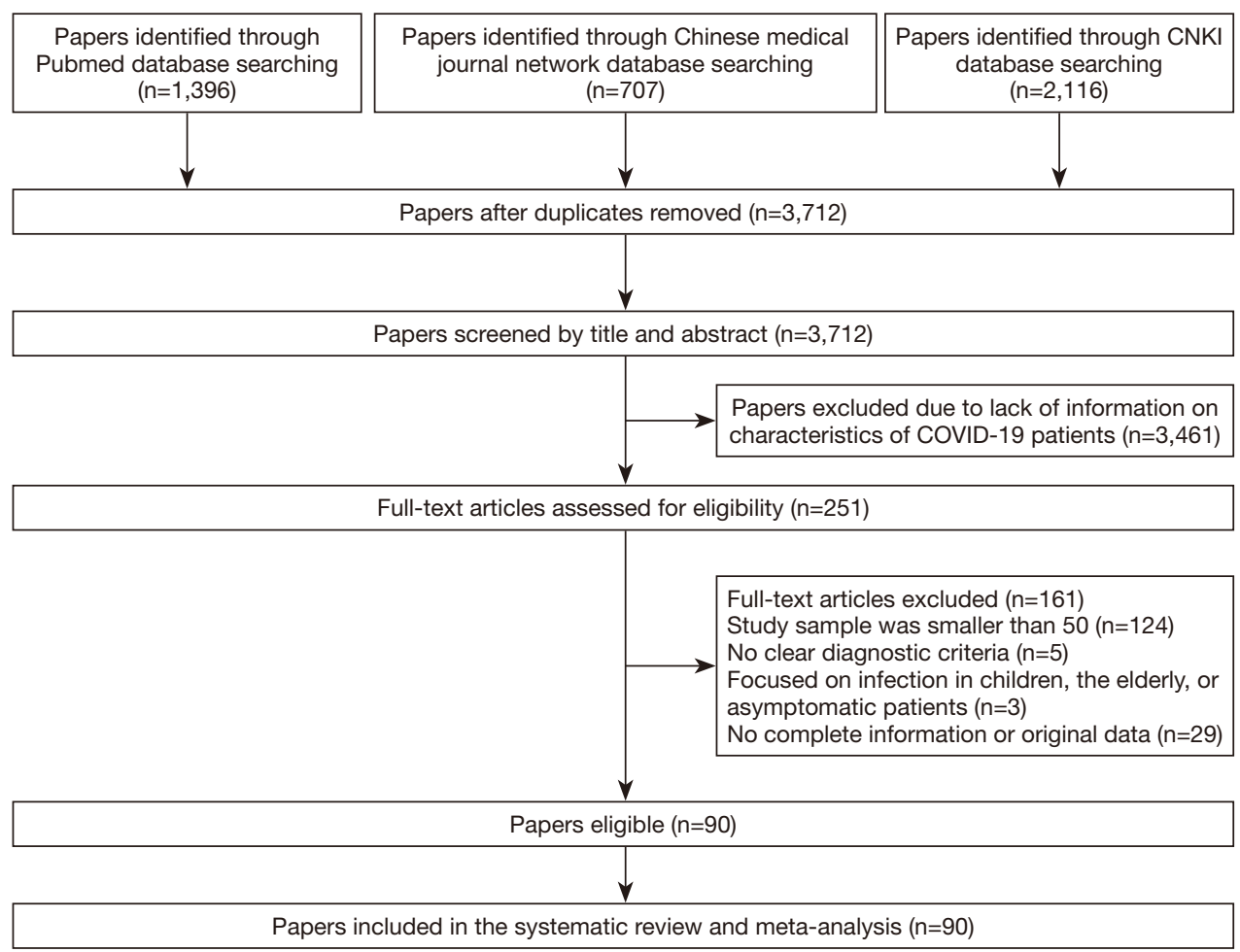

Figure 1 Flow diagram of the study selection process.

(26.4\%, 95\% CI, 21.4-31.4\%), sputum production $(22.7 \%$, 95\% CI, 18.2-27.2\%), chest distress (18.7\%, 95\% CI, $12.5-25.0 \%)$, and shortness of breath (18.5\%, 95\% CI, 12.9-24.2\%). The proportions of high fever, myalgia or arthralgia, dyspnoea, chills, and anorexia were also above 10\% (Figure 3).

Regarding the 32 frequently reported laboratory findings, the most common abnormalities were increased serum ferritin (74.2\%, 95\% CI, 64.9-83.5\%), high C-reactive protein (CRP) $(73.3 \%, 95 \%$ CI, 65.2-80.6\%), high ESR (72.2\%, 95\% CI, 62.1-82.3\%), decreased eosinophil (59.2\%, 95\% CI, 40.9-77.4\%), increased interleukin 6 (IL-6) $(58.2 \%$, 95\% CI, 32.7-83.6\%), lymphopenia (46.5\%, 95\% CI, 38.5-54.4\%), high lactic dehydrogenase (LDH) $(41.6 \%$, 95\% CI, 22.5-60.7\%), and hyperglycemia (40.1\%, 95\% CI, 29.5-50.6\%) (Figure 4).

\section{Chest CT findings}

The proportion of patients who had normal CT imaging features was $6.1 \%$. Eighty-two point two percent of the patients had bilateral lung involvement, $66.9 \%$ showed peripheral distribution, $73.1 \%$ showed multifocal involvement, and $62.1 \%$ showed subpleural distribution. Although all lung lobes can be involved, right lower lobe (65.1\%) and left lower lobe (70.4\%) were more likely to be involved. More than half of the COVID-19 patients had $>3$ lobes involved (57.9\%) (Figure 5).

The most common characteristics seen on chest CT were vascular enlargement $(64.3 \%, 95 \% \mathrm{CI}, 50.7-77.8 \%)$, ground-glass opacity (GGO) (60.7\%, 95\% CI, 51.1-70.3\%), thickened interlobular septa $(55.1 \%, 95 \%$ CI, 38.2-72.1\%), interstitial abnormalities (48.3\%, 95\% CI, 4-92.7\%), mixed GGO and consolidation (44.5\%, 95\% CI, 29-60\%), and air bronchogram (39.9\%, 95\% CI, 21.3-58.5\%). Pericardial effusion (4.4\%), pleural effusion (4.2\%), and enlarged mediastinal nodes $(2.9 \%)$ were rare (Figure 5$)$.

\section{Complications and outcomes}

Among the COVID-19 patients, respiratory failure was the most common complication $(30.7 \%$, 95\% CI, 10.2-51.1\%). In addition, $15.5 \%$ of the patients had acute respiratory distress syndrome (ARDS), $10.7 \%$ had acute cardiac injury, $4.5 \%$ had acute kidney injury, 9.6\% had secondary infection, and $4.6 \%$ had shock. The overall mortality was 


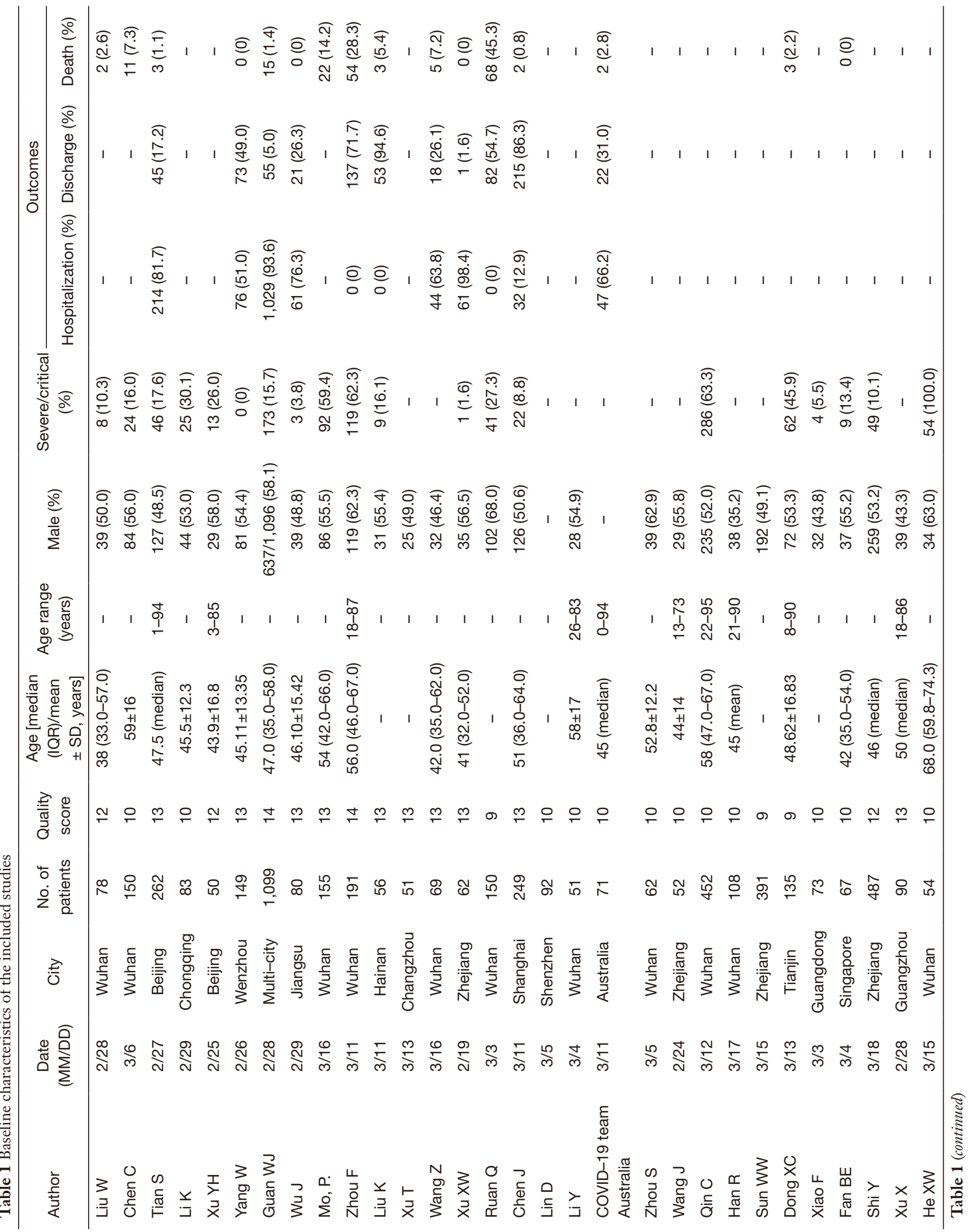




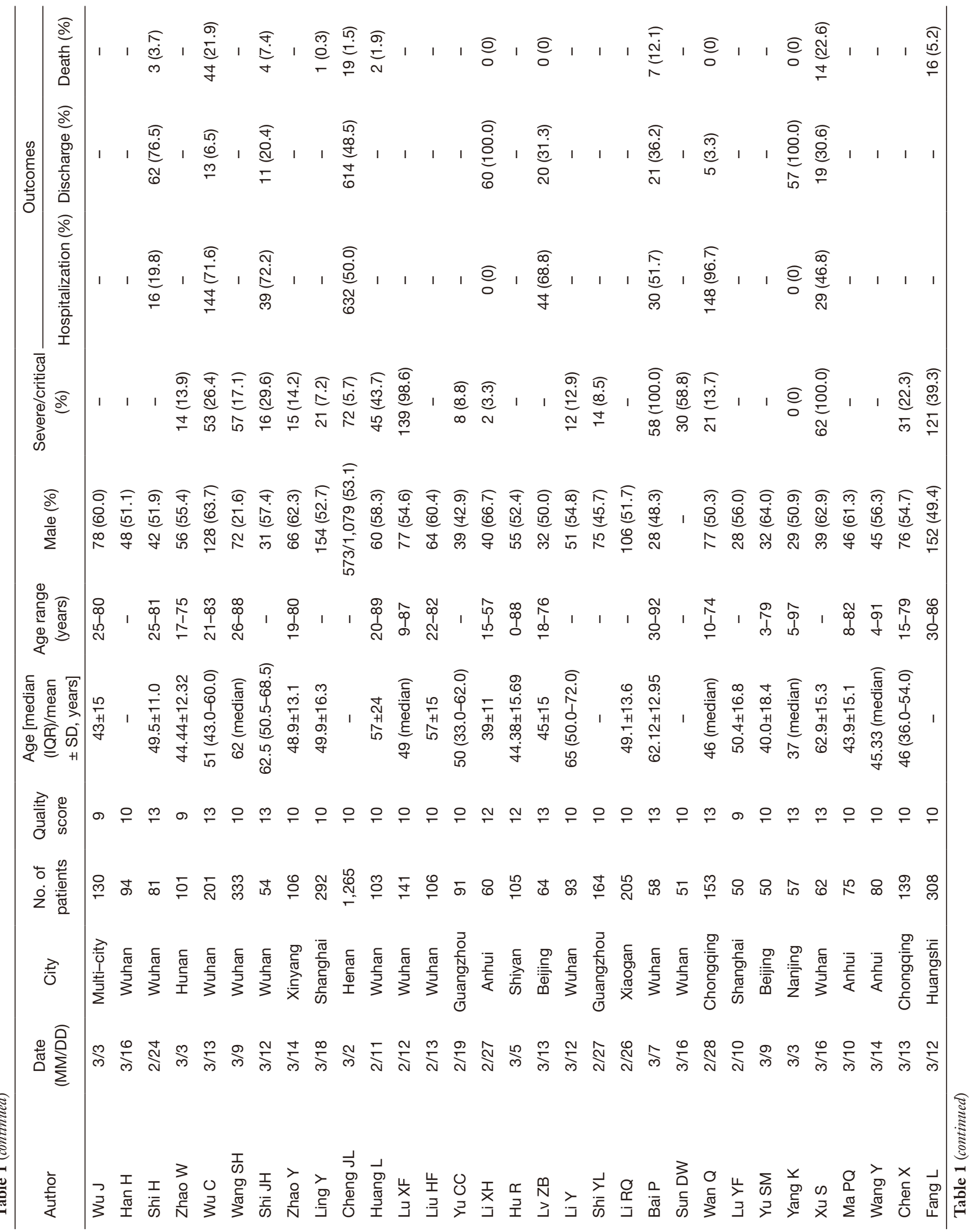




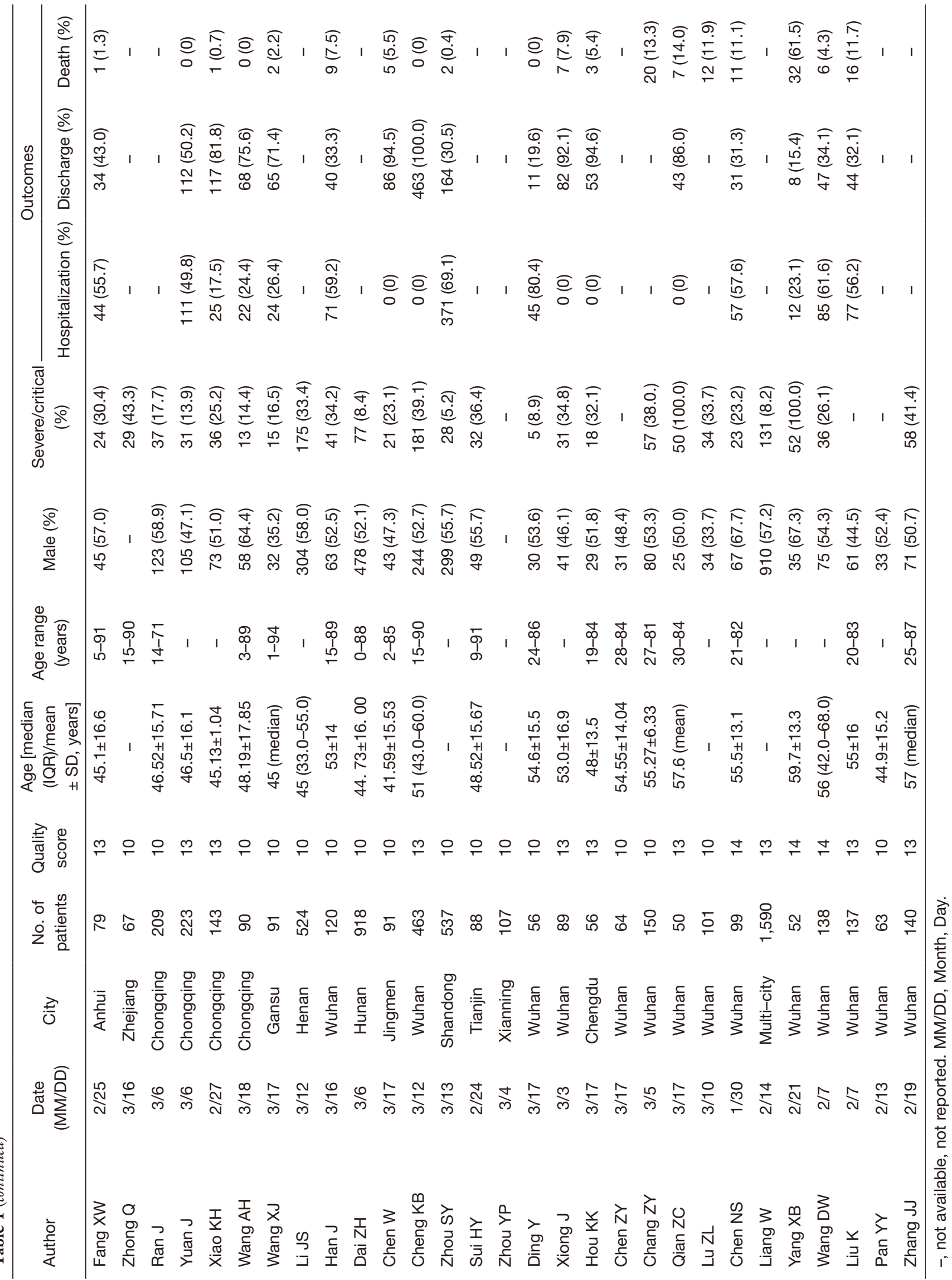




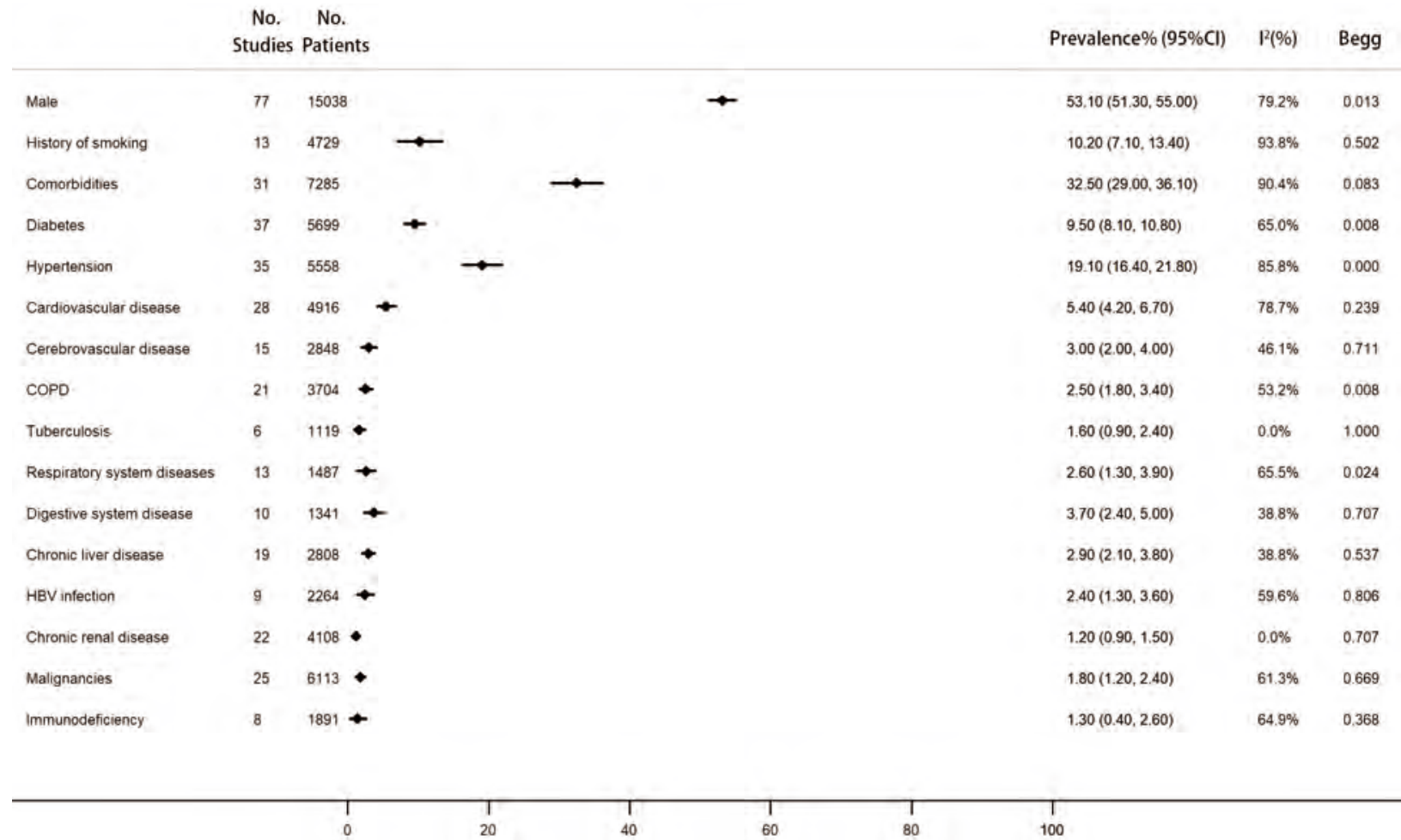

Figure 2 Meta-analysis of the sex ratio, smoking history, comorbidities of COVID-19 patients. COPD, chronic obstructive pulmonary disease; HBV, hepatitis B virus.

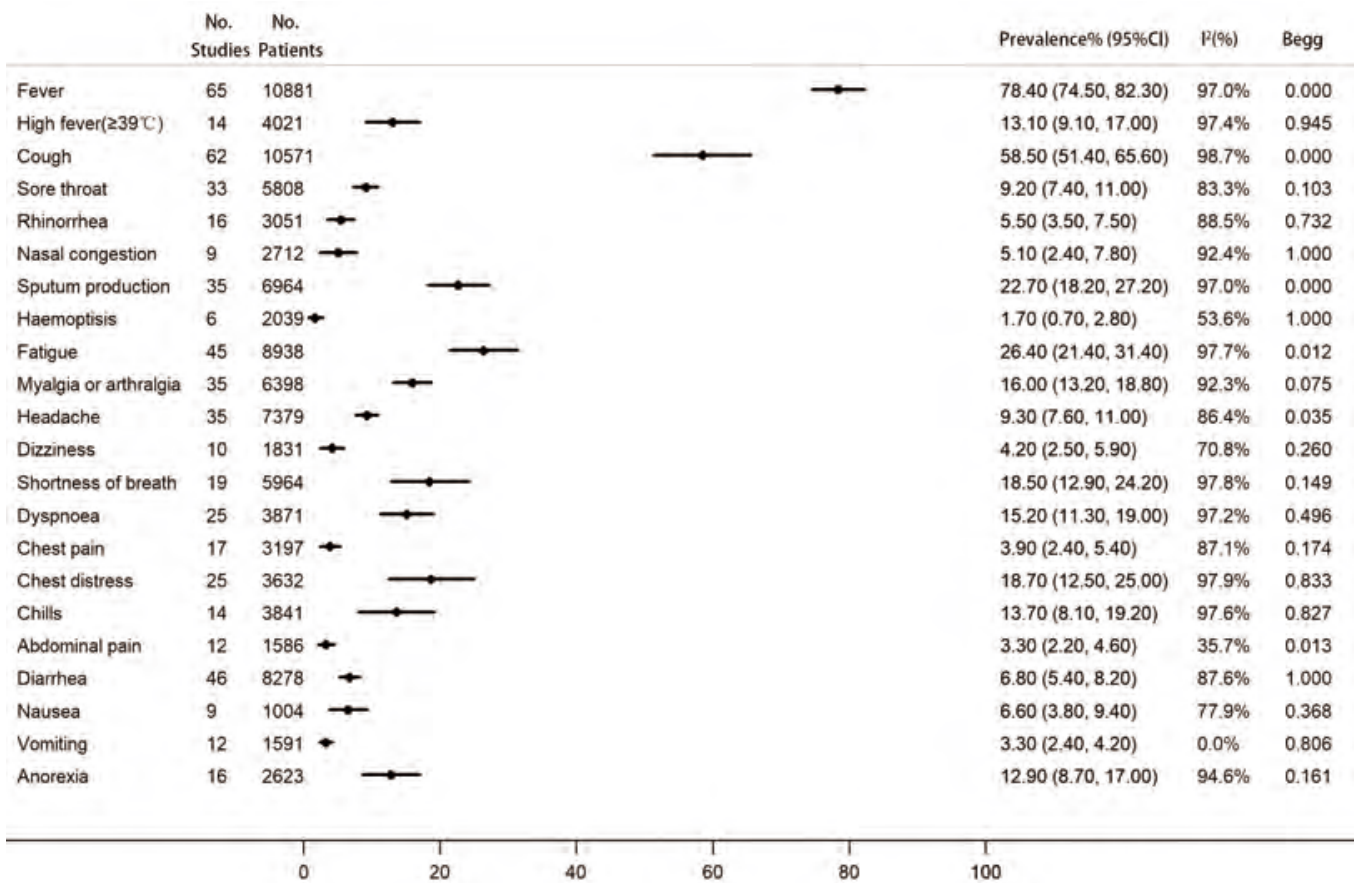

Figure 3 Meta-analysis of the prevalence of clinical symptoms in COVID-19 patients. 


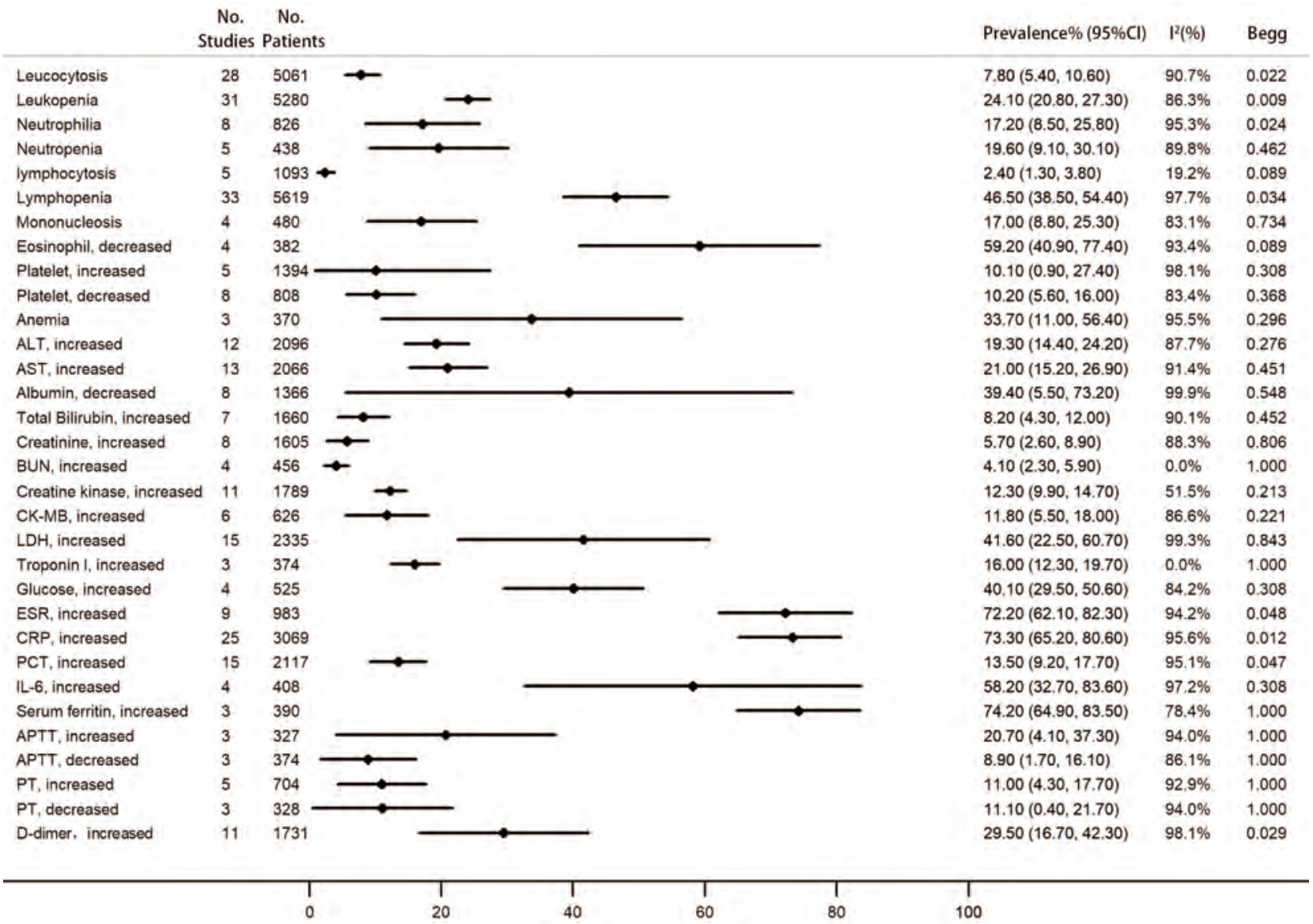

Figure 4 Meta-analysis of the proportion of laboratory abnormalities in COVID-19 patients. ALT, alanine aminotransferase; AST, aspartate aminotransferase; BUN, blood urea nitrogen; CK-MB, creatine kinase-MB; LDH, lactic dehydrogenase; ESR, erythrocyte sedimentation rate; CRP, C-reactive protein; PCT, procalcitonin; IL-6, interleukin 6; APTT, activated partial thromboplastin time; PT, prothrombin time.

\section{2\% (95\% CI, 2.6-6.3\%) (Figure 6).}

\section{Subgroup analysis}

According to the subgroup analysis, the prevalence of comorbidities, clinical symptoms, laboratory abnormalities, and complications most was higher in Wuhan than in other cities. However, the proportions of patients who had a history of smoking and abnormal chest CT characteristics (such as GGO, consolidation, and pleural effusion) were higher in other cities. Besides, we also found a significantly higher CFR in Wuhan than in other cities $(10.4 \%, 95 \%$ CI, $6.3-15.5 \%$; versus $1.3 \%, 95 \%$ CI, $0.7-1.9 \%$ ) (Table 2).

\section{Comparison between severe and non-severe cases and risk factors of severe illness}

Among the included 90 studies, 30 and 35 studies reported information of non-severe and severe cases, respectively. The proportion of male was significantly higher in severe patients compared with non-severe patients $(60.9 \%, 95 \%$ CI, $57.3-64.4 \%$; versus $49.5 \%$, $95 \%$ CI, $46.6-52.4 \%)$. We compared the differences in the comorbidities, clinical symptoms, laboratory abnormalities, image findings, and complications between the two groups. Most of the proportions were higher among severe cases, except for chronic liver disease and headache. In addition, the 


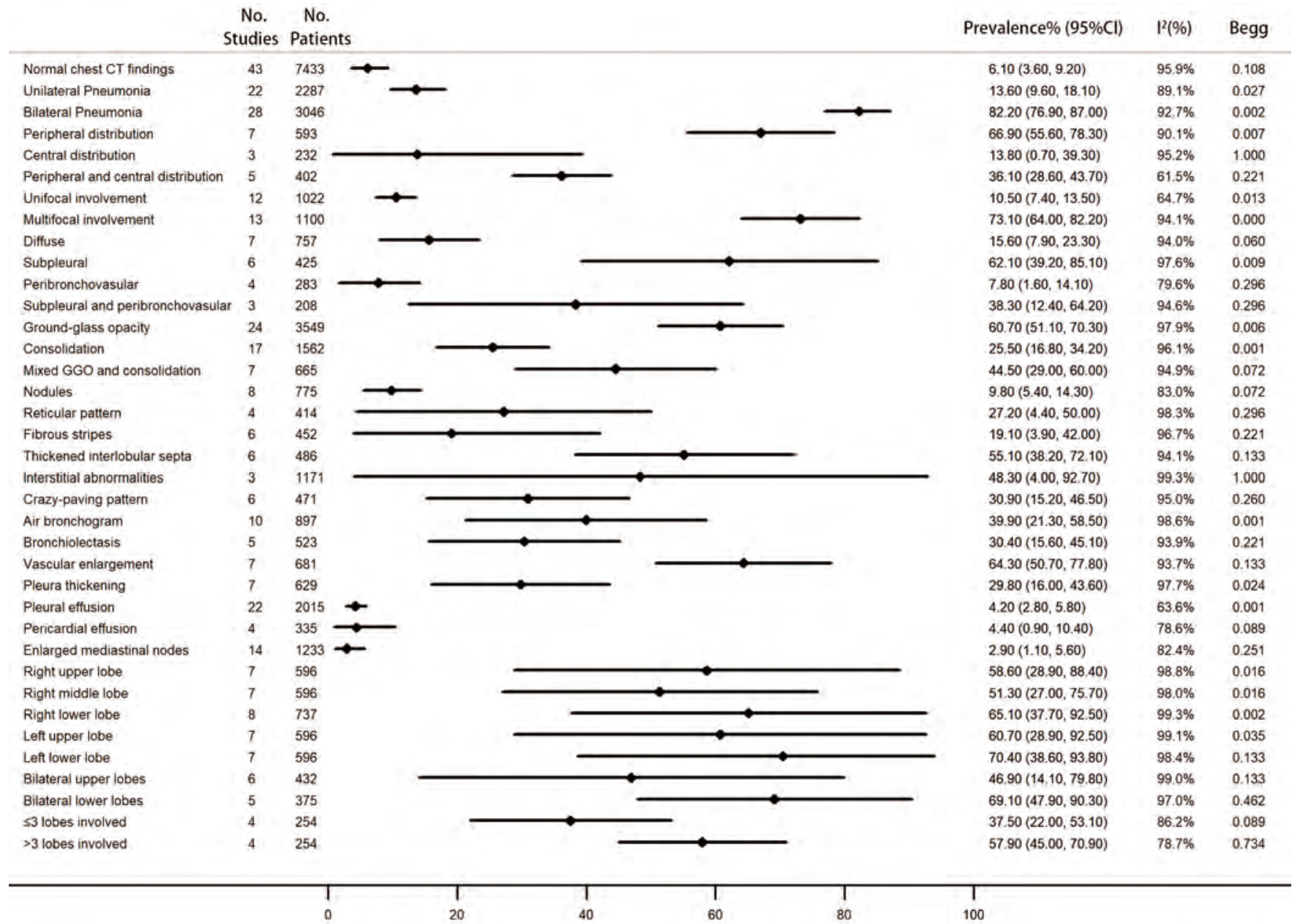

Figure 5 Meta-analysis of the prevalence of chest CT findings of COVID-19 patients. GGO, ground-glass opacity.

mortality rate in severe patients was significantly higher than that in non-severe patients $(12.6 \%, 95 \%$ CI, 6.6$20.3 \%$; versus $0.2 \%, 95 \%$ CI, $0.1-0.4 \%$ ) (Table 3 ).

The results obtained by calculating the OR were similar to those obtained by direct comparison of prevalence. Male (OR 1.43, $\mathrm{P}<0.0001$ ), history of smoking (OR 1.55, $\mathrm{P}=0.005)$, and comorbidities $(\mathrm{OR} 2.87, \mathrm{P}<0.00001)$ such as hypertension, diabetes, cardiovascular disease, cerebrovascular disease, chronic obstructive pulmonary disease (COPD), malignancies, and chronic renal disease might influence the prognosis of the patients with SARSCoV-2 infection (Figure S1, Table 4). Most clinical symptoms such as fever, high fever, cough, sputum production, fatigue, shortness of breath, dyspnea, and abdominal pain were linked to the severity of the disease, while there was no statistical difference between the two groups in sore throat, myalgia or arthralgia, headache, chest distress, and diarrhea (Figure S2, Table 4). Many laboratory indicators implied the deterioration of disease, such as leucocytosis, lymphopenia, platelet, alanine aminotransferase (ALT), aspartate aminotransferase (AST), albumin, creatinine, creatine kinase (CK), LDH, CRP, procalcitonin (PCT), and D-dimer. However, the prevalence of leukopenia was not significantly higher in severe cases than in non-severe cases (OR 1.32, $\mathrm{P}=0.35$ ) (Figure S3, Table 4). For chest CT findings, the risk of bilateral pneumonia, consolidation, pleural effusion, and enlarged mediastinal nodes was higher in severe patients than in non-severe patients. But the analysis did not present that the difference in GGO between severe and non-severe patients was statistically significant (OR 1.03, $\mathrm{P}=0.92$ ) (Figure S4, Table 4). 


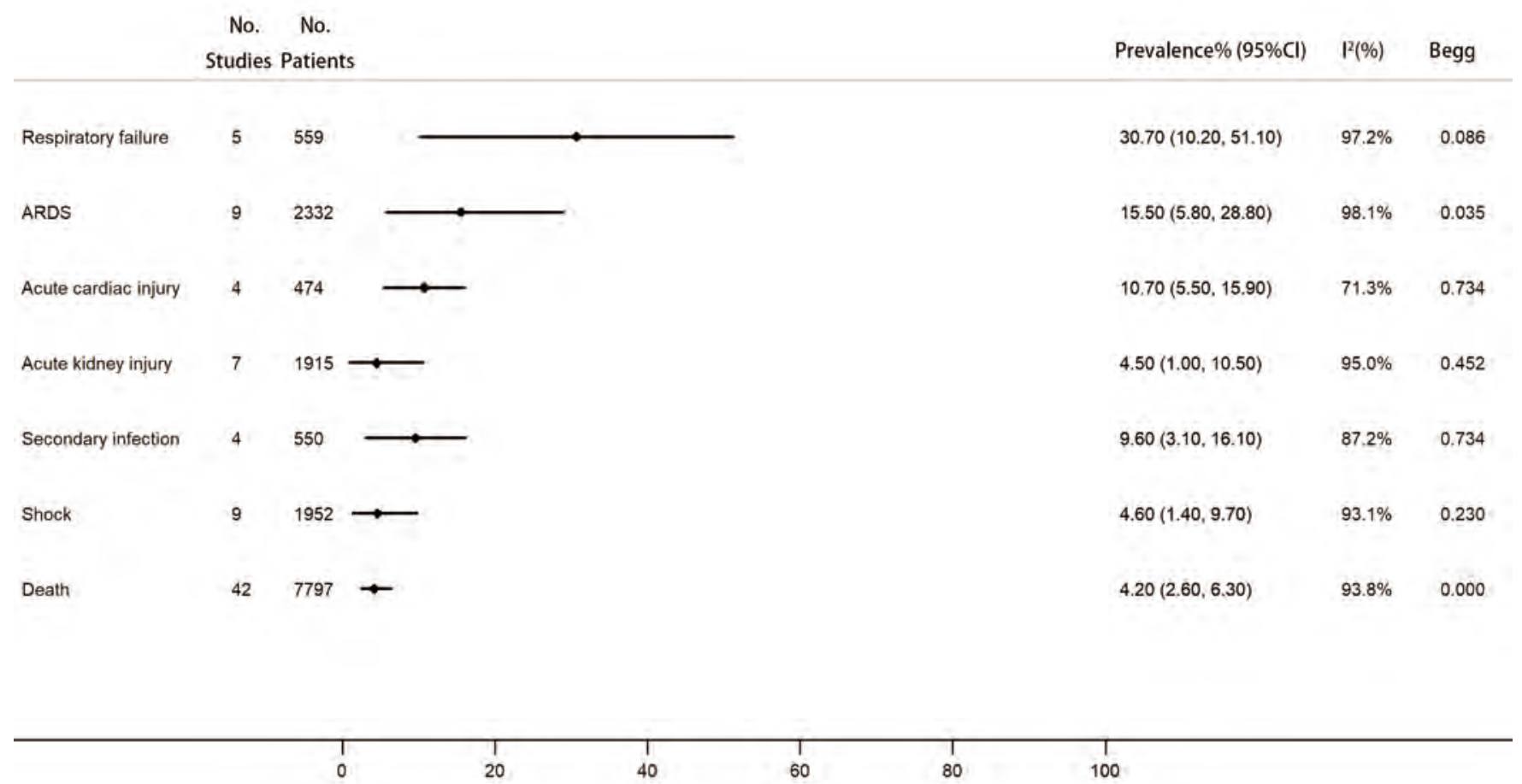

Figure 6 Meta-analysis of the prevalence of complications and clinical outcomes of COVID-19 patients. ARDS, acute respiratory distress syndrome.

Table 2 Subgroup analysis comparing studies from Wuhan and those from other cities

\begin{tabular}{|c|c|c|c|c|c|c|c|c|}
\hline \multirow[b]{2}{*}{ Variables } & \multicolumn{4}{|c|}{ Wuhan } & \multicolumn{4}{|c|}{ Other cities } \\
\hline & No. reports & No. patients & $\begin{array}{l}\text { Prevalence\% } \\
\qquad(95 \% \mathrm{Cl})\end{array}$ & $\mathrm{I}^{2}(\%)$ & No. reports & No. patients & $\begin{array}{l}\text { Prevalence\% } \\
\qquad(95 \% \mathrm{Cl})\end{array}$ & $\mathrm{I}^{2}(\%)$ \\
\hline History of smoking & 5 & 1,016 & $4.3(1.9-6.7)$ & 68.6 & 6 & 1,038 & $17.1(10.6-23.5)$ & 86.9 \\
\hline Comorbidities & 9 & 1,409 & $40.5(30.9-50.1)$ & 92.9 & 20 & 3,187 & $29.7(26.1-33.3)$ & 78.5 \\
\hline Hypertension & 18 & 2,482 & $23(18.5-27.6)$ & 87.1 & 16 & 1,977 & $14.9(11.9-17.8)$ & 70.9 \\
\hline Cardiovascular disease & 15 & 2,253 & $7.4(5.8-9)$ & 52.8 & 12 & 1,564 & $3.2(1.8-4.6)$ & 63.6 \\
\hline $\begin{array}{l}\text { Cerebrovascular } \\
\text { disease }\end{array}$ & 10 & 1,414 & $3.9(2.6-5.2)$ & 34.7 & 4 & 335 & $2.2(0.6-3.7)$ & 0.0 \\
\hline Malignancies & 14 & 2,044 & $3(1.8-4.3)$ & 70.9 & 9 & 1,380 & $1.2(0.5-2)$ & 31.1 \\
\hline Fever & 23 & 2,818 & $85.1(81.8-88.5)$ & 89.6 & 41 & 6,982 & 75.8 (71.3-80.3) & 95.7 \\
\hline High fever $\left(\geq 39^{\circ} \mathrm{C}\right)$ & 5 & 642 & $30.3(7.7-52.9)$ & 98.4 & 8 & 2,298 & $4.1(2.2-6)$ & 80.1 \\
\hline Cough & 21 & 2,557 & $63.4(50.1-76.7)$ & 98.7 & 40 & 6,915 & $55.7(46.9-64.5)$ & 98.7 \\
\hline
\end{tabular}

Table 2 (continued) 
Table 2 (continued)

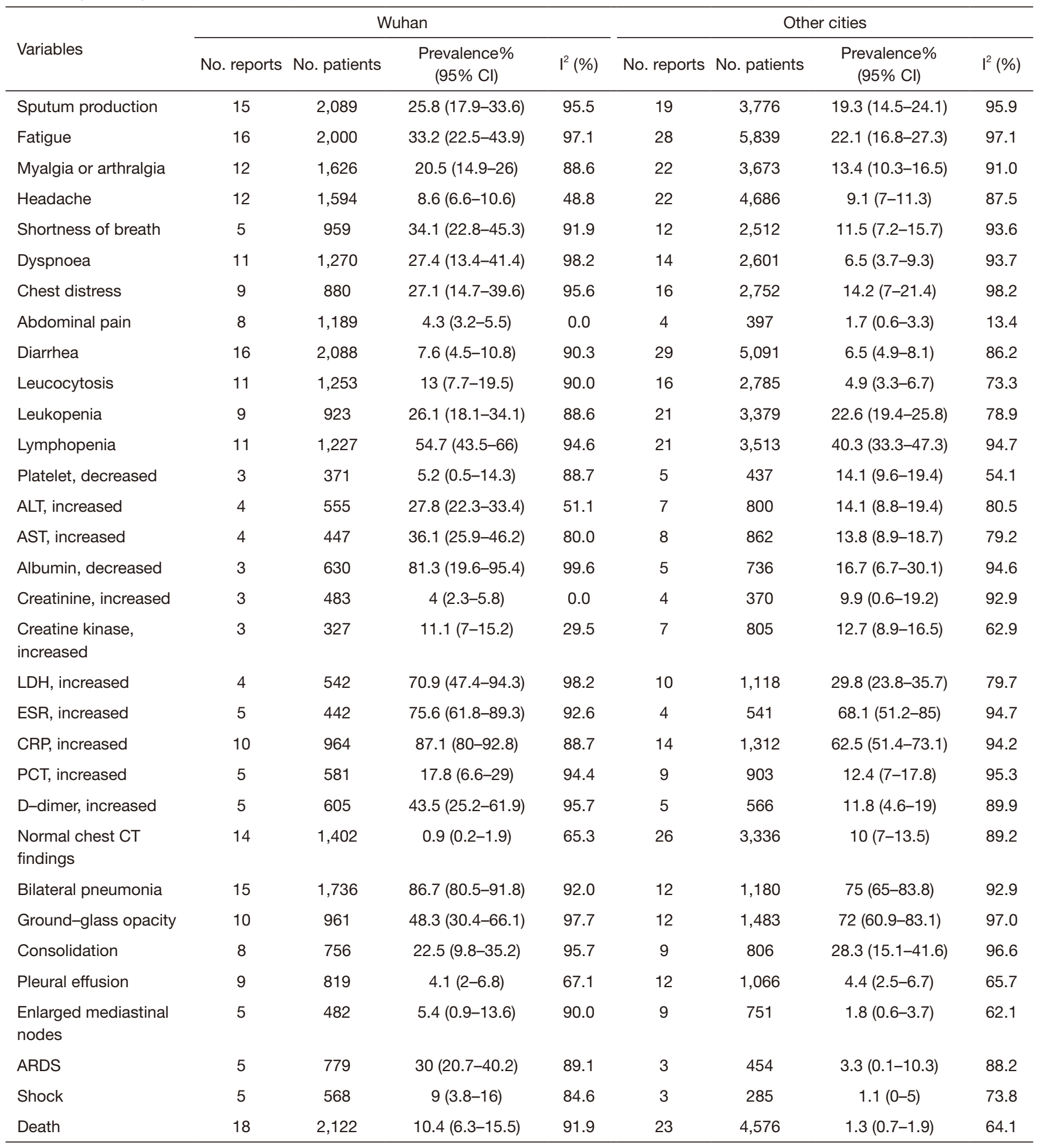

COPD, chronic obstructive pulmonary disease; ALT, alanine aminotransferase; AST, aspartate aminotransferase; LDH, lactic dehydrogenase; CRP, C-reactive protein; PCT, procalcitonin; ARDS, acute respiratory distress syndrome. 
Table 3 Comparison between severe COVID-19 patients and non-severe COVID-19 patients

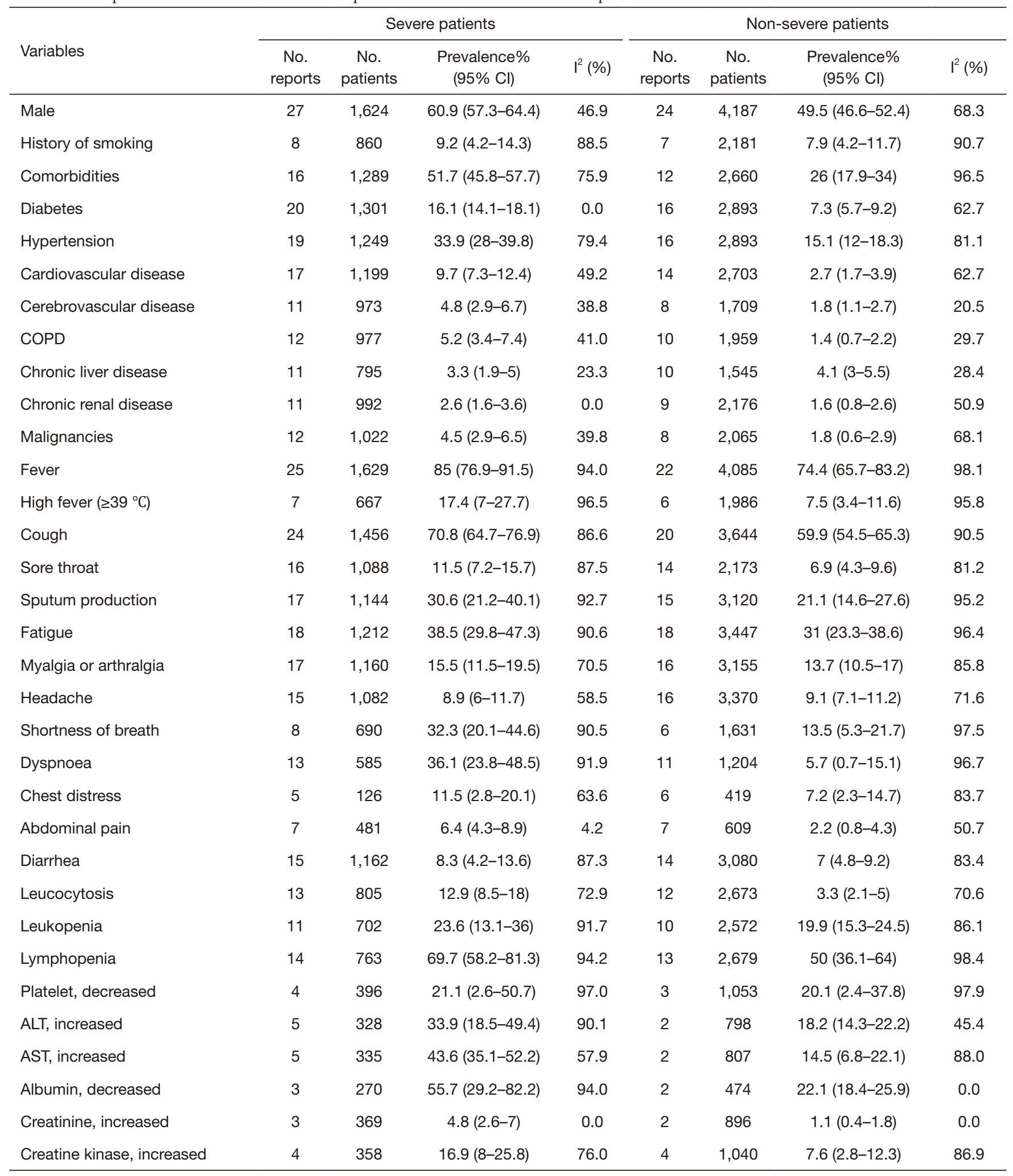

Table 3 (continued) 
Table 3 (continued)

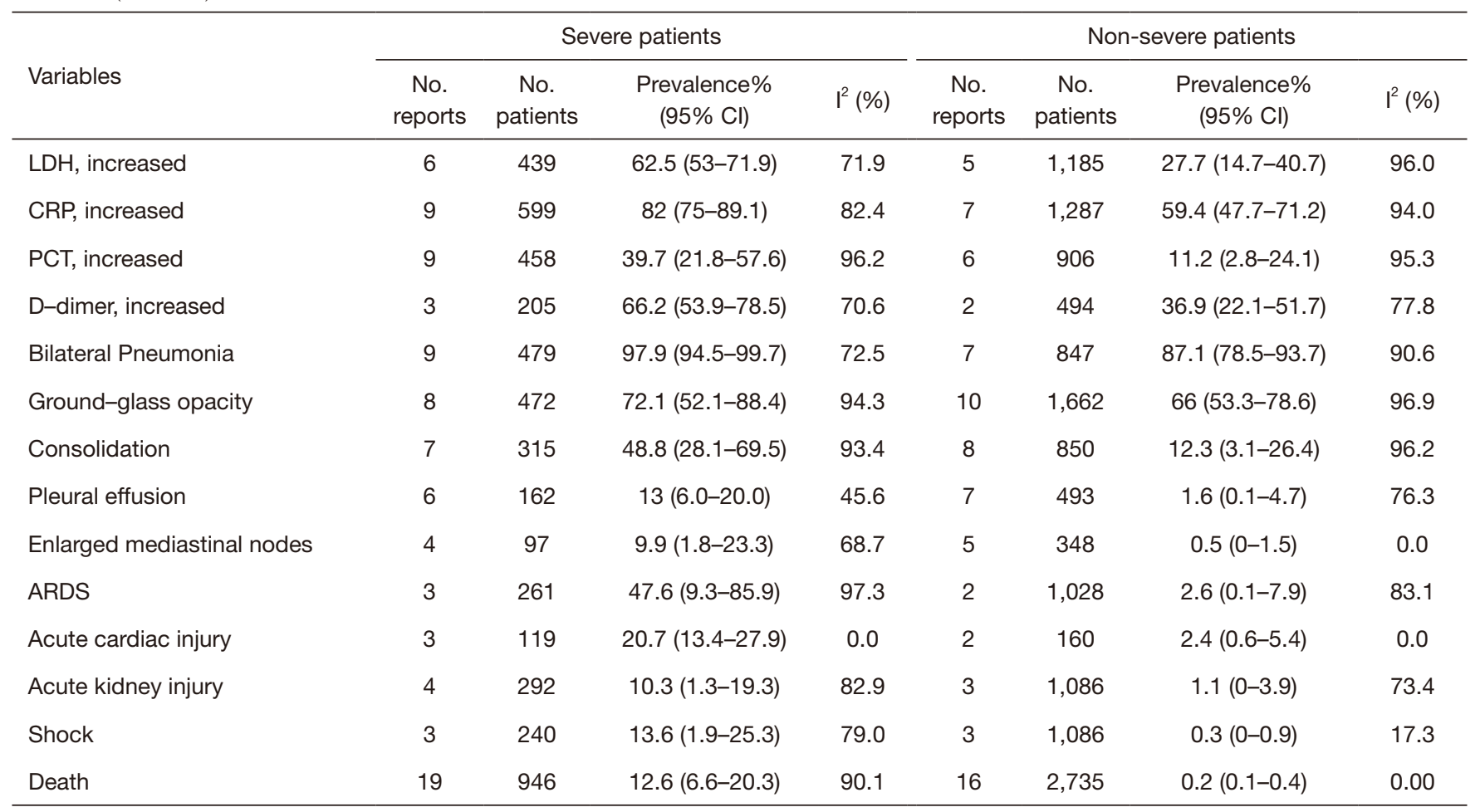

COPD, chronic obstructive pulmonary disease; ALT, alanine aminotransferase; AST, aspartate aminotransferase; LDH, lactic dehydrogenase; CRP, C-reactive protein; PCT, procalcitonin; ARDS, acute respiratory distress syndrome.

\section{Heterogeneity and publication bias}

We meta-analyzed 114 features of COVID-19 patients. Among them, $36(31.6 \%)$ presented publication bias (Figures $2-6, \mathrm{P}<0.05$ by Begg's test). In the meta-analysis of prevalence, most of the analyses had high heterogeneity (Figures 2-6). And in the meta-analysis of risk factors for severity, most had low or moderate heterogeneity (Figures S1-S4).

\section{Discussion}

Based on the information from 90 studies with 16,526 laboratory-confirmed COVID-19 patients, our systematic review and meta-analysis provided a comprehensive description of the characteristics of COVID-19 patients, including comorbidities, clinical symptoms, laboratory characteristics, chest CT features, and complications and identified the risk factors of severe disease.

In our article, the overall CFR of confirmed patients was $4.2 \%$, which is close to the estimate $(4.8 \%)$ reported by the World Health Organization as of March 30, 2020
(33,106 deaths among 693,224 confirmed cases) (2). The Chinese Center for Disease Control and Prevention (China CDC) reported that the overall CFR was $4.1 \%$ among 81,518 confirmed patients in mainland China as of March 30, 2020, and the CFR in Wuhan was 5.1\% (2,548 deaths among 50,006 confirmed cases) (100). Our subgroup analysis also found a CFR of $10.4 \%$ in Wuhan comparing to $1.3 \%$ in other cities. This may indicate that earlier outbreak caused more deaths and effective disease control and prevention measures can significantly decline the CFR of communicable diseases.

The population is generally susceptible to COVID-19 at all ages, the median age we analyzed was 48.8 years. We found that the proportion of male patients was $53.1 \%$ and it was significantly higher in severe cases than in non-severe cases. A previous meta-analysis found a similar finding that male was a risk factor for severe illness in COVID-19 patients (101). But another study did not find significant differences in CFR and the proportion of severe patients between male and female (22). Some studies explained that there are differences between the immune system of men 
Table 4 Meta-analysis of risk factors for severity

\begin{tabular}{|c|c|c|c|c|}
\hline Variables & No. of studies & No. of patients & OR $[95 \% \mathrm{Cl}]$ & $P$ value \\
\hline History of smoking & 7 & 2,989 & $1.55[1.14,2.10]$ & 0.005 \\
\hline \multicolumn{5}{|l|}{ Comorbidities } \\
\hline Comorbidities & 12 & 3,727 & $2.87[2.13,3.86]$ & $<0.00001$ \\
\hline Diabetes & 15 & 3,854 & $2.46[1.77,3.40]$ & $<0.00001$ \\
\hline Cardiovascular disease & 13 & 3,612 & $3.28[2.27,4.75]$ & $<0.00001$ \\
\hline Cerebrovascular disease & 8 & 2,453 & $2.78[1.49,5.19]$ & 0.001 \\
\hline COPD & 10 & 2,820 & $3.60[2.08,6.23]$ & $<0.00001$ \\
\hline Chronic renal disease & 9 & 3,048 & $1.94[1.09,3.42]$ & 0.02 \\
\hline \multicolumn{5}{|l|}{ Clinical symptoms } \\
\hline Fever & 20 & 5,266 & $1.78[1.31,2.42]$ & 0.0002 \\
\hline High fever $\left(\geq 39{ }^{\circ} \mathrm{C}\right)$ & 6 & 2,603 & $2.25[1.42,3.58]$ & 0.0006 \\
\hline Cough & 19 & 4,760 & $1.63[1.28,2.09]$ & 0.0001 \\
\hline Sore Throat & 13 & 2,983 & $1.22[0.82,1.82]$ & 0.32 \\
\hline Sputum production & 15 & 4,144 & $1.40[1.08,1.81]$ & 0.01 \\
\hline Fatigue & 16 & 4,375 & $1.57[1.21,2.04]$ & 0.0008 \\
\hline Abdominal pain & 7 & 1,090 & $2.60[1.05,6.39]$ & 0.04 \\
\hline Diarrhea & 12 & 3,896 & $1.34[0.95,1.88]$ & 0.09 \\
\hline \multicolumn{5}{|l|}{ Laboratory abnormalities } \\
\hline Leucocytosis & 10 & 3,144 & $2.97[2.15,4.10]$ & $<0.00001$ \\
\hline Leukopenia & 9 & 3,058 & $1.32[0.74,2.35]$ & 0.35 \\
\hline Lymphopenia & 11 & 3,153 & $2.78[1.85,4.19]$ & $<0.00001$ \\
\hline Platelet, decreased & 3 & 1,399 & $2.35[1.43,3.88]$ & 0.0008 \\
\hline ALT, increased & 2 & 964 & $2.14[1.03,4.45]$ & 0.04 \\
\hline AST, increased & 2 & 980 & $3.53[2.02,6.17]$ & $<0.00001$ \\
\hline Albumin, decreased & 2 & 686 & $2.84[1.34,6.02]$ & 0.006 \\
\hline Creatinine, increased & 2 & 1,215 & $3.63[1.63,8.05]$ & 0.002 \\
\hline
\end{tabular}

Table 4 (continued) 
Table 4 (continued)

\begin{tabular}{|c|c|c|c|c|}
\hline Variables & No. of studies & No. of patients & OR $[95 \% \mathrm{Cl}]$ & $P$ value \\
\hline LDH, increased & 5 & 1,566 & $3.70[2.03,6.73]$ & $<0.0001$ \\
\hline CRP, increased & 6 & 1,668 & $3.40[2.23,5.17]$ & $<0.00001$ \\
\hline PCT, increased & 6 & 1,194 & $5.39[3.51,8.28]$ & $<0.00001$ \\
\hline \multicolumn{5}{|l|}{ CT findings } \\
\hline Bilateral Pneumonia & 7 & 1,224 & $3.16[1.37,7.29]$ & 0.007 \\
\hline Ground-glass opacity & 8 & 1,962 & $1.03[0.56,1.88]$ & 0.92 \\
\hline Consolidation & 7 & 1,057 & $6.70[3.03,14.78]$ & $<0.00001$ \\
\hline
\end{tabular}

COPD, chronic obstructive pulmonary disease; ALT, alanine aminotransferase; AST, aspartate aminotransferase; LDH, lactic dehydrogenase; CRP, C-reactive protein; PCT, procalcitonin.

and women which may cause a high risk of viral infection for men $(102,103)$. Patients with underlying diseases have lower immunity and are more likely to be severely ill. In our study, hypertension (19.1\%), diabetes (9.5\%), and cardiovascular disease $(5.4 \%)$ were the most common comorbidities, and the proportion was higher among severe patients. The finding was consistent with another study that found the most prevalent comorbidities were hypertension $(21.1 \%)$ and diabetes $(9.7 \%)$, followed by cardiovascular diseases $(8.4 \%)$ and hypertension, cardiovascular disease, and respiratory system disease were independent risk factors of severe disease in patients with SARS-CoV-2 infection (104).

Guan et al. and Chen et al. reported that fever and cough were the most common clinical manifestations, and nausea or vomiting and diarrhea were uncommon $(11,98)$. Our study also reached a similar conclusion that the most prevalent symptoms were fever (78.4\%) and cough (58.5\%), however, the proportion was a little lower than the previous studies (fever, 87-88\%; cough $67.8-82 \%$ ). And gastrointestinal symptoms were rare. Comparing to non-severe patients, most symptoms were more common in severe patients, particularly shortness of breath and dyspnoea. It suggested that severe patients might have worse lung function. The most common laboratory abnormalities showed in our article were increased serum ferritin (74.2\%,), high CRP (73.3\%), high ESR (72.2\%), decreased eosinophil (59.2\%), increased interleukin 6
(58.2\%), lymphopenia (46.5\%), high LDH (41.6\%), and hyperglycemia (40.1\%). Compared with non-severe patients, the laboratory abnormalities occurred more frequently in severe patients. And we also proposed a link between some specific laboratory indicators (leucocytosis, lymphopenia, platelet, ALT, AST, albumin, creatinine, CK, LDH, CRP, PCT, and D-dimer) and disease severity of COVID-19 patients. This finding suggested that the pathophysiological hallmark of COVID-19 tend to be the sustained inflammatory response and cytokine storm which is similar to those previously found in patients infected with the SARS-CoV and MERS-CoV, and severe inflammation would lead to immune deficiency, hepatic damage, myocardial damage, kidney damage, and coagulation activation (94). A review demonstrated that the evaluation of lymphocyte count, biomarkers (serum PCT and ferritin), and inflammatory indices, such as LDH, CRP, and IL-6 might contribute to identify patients with poor prognosis (105). This conclusion was consistent with our comparison between severe and nonsevere patients. Regarding serum ferritin, two studies presented that higher serum ferritin was related to disease progression $(14,106)$, but no study supported the general elevation of serum ferritin in patients with SARS-CoV-2 infection. We just included 3 studies in the meta-analysis of the prevalence of increased serum ferritin, so the result needed more studies to confirm. 
Although the imaging manifestations of viral pneumonia are generally considered to be non-specific (107), with the in-depth studies of the imaging features of COVID-19, some relatively special CT characteristics were found $(42,59,108,109)$. And there are obvious differences between patients of different clinical types and stages $(59,109)$. According to previous studies, typical CT findings of COVID-19 patients were bilateral lung involvement with diffuse distribution and lesions mostly were located peripherally $(42,108)$. The main patterns were groundglass opacity, air bronchograms, and interstitial abnormalities. And pulmonary cavitation, discrete pulmonary nodules, lymphadenopathy, and pleural effusions were absent $(42,108)$. In our study, the finding was similar. Most cases had bilateral lung involvement and presented peripheral and subpleural distribution, with multifocal involvement. More than half of patients had $>3$ lobes involved and the right lower lobe and the left lower lobe were more likely to be involved. The most common CT features were vascular enlargement, ground-glass opacity, thickened interlobular septa, interstitial abnormalities, mixed GGO and consolidation, and air bronchogram. Pericardial effusion, pleural effusion, and enlarged mediastinal nodes were rare. In addition, our analysis showed that patients presented with bilateral pneumonia, consolidation, pleural effusion, and enlarged mediastinal nodes faced a higher risk of developing a serious illness. In the whole, Chest CT acts a crucial part in the diagnosis and treatment for patients with SARS-CoV-2 infection.

With regard to the complications, the most common were respiratory failure (30.7\%) and ARDS (15.5\%), but also, a small percentage of patients had acute cardiac injury, acute kidney injury, secondary infection, and shock. Compared with non-severe cases, severe cases significantly had worse disease progression, particularly ARDS (2.6\% versus $47.6 \%)$ (Table 3). Thus, early identification and timely treatment of severe patients would better improve the prognosis.

Although some systematic reviews and meta-analyses which studied the features of patients with COVID-19 have been published $(21,22)$, our study updated the comprehensive information of clinical characteristics of patients with COVID-19 worldwide and analyzed the risk factors of severe illness. High quality and large sample size of the included studies were the strengths of our study. We also conducted a subgroup analysis based on the area. Nevertheless, our review had a few limitations. First, most of the included studies were single-center retrospective studies which were difficult to control the influence of confounding factors. Second, we found significant heterogeneity and publication bias between studies. Third, most included studies were from China, data from other countries are required. Lastly, some detailed information, such as clinical outcomes and prognosis, was incomplete. Based on updated data all around the world, in-depth studies need to be conducted.

\section{Conclusions}

In summary, most patients with COVID-19 have fever and cough with lymphopenia and increased inflammatory indices, and the main CT feature is GGO involved bilateral lung. Patients with comorbidities and worse clinical symptoms, laboratory characteristics, and CT findings tend to have poor disease progression and outcome. COVID-19 is an emerging pandemic of global public health concern. So, the prevention and control of the disease spread are imminent. In addition, more researches are required to elucidate the pathogenesis and the risk factors for severe cases and death.

\section{Acknowledgments}

Funding: This work was supported by grants from the National Natural Science Foundation of China (grant number 81401903,81572937 and 81572273 ); the $16^{\text {th }}$ batch "Summit of the Six Top Talents" Program of Jiangsu Province (grant number WSN-154); China Postdoctoral Science Foundation $12^{\text {th }}$ batch Special fund (Postdoctoral number: 45786);China Postdoctoral Science Foundation $64^{\text {th }}$ batch (Postdoctoral number: 45786); Jiangsu Provincial Postdoctoral Science Foundation (grant number 2018K049A); the Natural Science Foundation of Jiangsu province (grant number BK20180139 and BK20161386); Jiangsu Provincial Medical Youth Talent (grant number QNRC2016125), and the Nanjing Medical Science and Technology Development Project (No. ZKX17044), the Jiangsu Provincial Key Research and Development Program (No. BE2016721).

\section{Footnote}

Reporting Checklist: The authors have completed the PRISMA reporting checklist. Available at http://dx.doi. org/10.21037/apm-20-1863

Conflicts of Interest: All authors have completed the ICMJE 
uniform disclosure form (available at http://dx.doi. org/10.21037/apm-20-1863). The authors have no conflicts of interest to declare.

Ethical Statement: The authors are accountable for all aspects of the work in ensuring that questions related to the accuracy or integrity of any part of the work are appropriately investigated and resolved.

Open Access Statement: This is an Open Access article distributed in accordance with the Creative Commons Attribution-NonCommercial-NoDerivs 4.0 International License (CC BY-NC-ND 4.0), which permits the noncommercial replication and distribution of the article with the strict proviso that no changes or edits are made and the original work is properly cited (including links to both the formal publication through the relevant DOI and the license). See: https://creativecommons.org/licenses/by-nc-nd/4.0/.

\section{References}

1. Wang C, Horby PW, Hayden FG, et al. A novel coronavirus outbreak of global health concern. Lancet 2020;395:470-3.

2. Coronavirus disease 2019 (COVID-19) Situation Report - 70. Available online: https://www.who.int/docs/defaultsource/coronaviruse/situation-reports/20200330-sitrep70-covid-19.pdf?sfvrsn=7e0fe3f8_4

3. Zhu N, Zhang D, Wang W, et al. A Novel Coronavirus from Patients with Pneumonia in China, 2019. N Engl J Med 2020;382:727-33.

4. Wu Z, McGoogan JM. Characteristics of and Important Lessons From the Coronavirus Disease 2019 (COVID-19) Outbreak in China: Summary of a Report of 72314 Cases From the Chinese Center for Disease Control and Prevention. JAMA 2020;323:1239-42.

5. Liu W, Tao ZW, Wang L, et al. Analysis of factors associated with disease outcomes in hospitalized patients with 2019 novel coronavirus disease. Chin Med J (Engl) 2020;133:1032-8.

6. Chen C, Chen C, Yan JT, et al. Analysis of myocardial injury in patients with COVID-19 and association between concomitant cardiovascular diseases and severity of COVID-19. Zhonghua Xin Xue Guan Bing Za Zhi 2020;48:567-71.

7. Tian S, Hu N, Lou J, et al. Characteristics of COVID-19 infection in Beijing. J Infect 2020;80:401-6.

8. Li K, Wu J, Wu F, et al. The Clinical and Chest CT
Features Associated With Severe and Critical COVID-19

Pneumonia. Invest Radiol 2020;55:327-31.

9. $\mathrm{Xu} \mathrm{YH,} \mathrm{Dong} \mathrm{JH,} \mathrm{An} \mathrm{WM,} \mathrm{et} \mathrm{al.} \mathrm{Clinical} \mathrm{and}$ computed tomographic imaging features of novel coronavirus pneumonia caused by SARS-CoV-2. J Infect 2020;80:394-400.

10. Yang W, Cao Q, Qin L, et al. Clinical characteristics and imaging manifestations of the 2019 novel coronavirus disease (COVID-19):A multi-center study in Wenzhou city, Zhejiang, China. J Infect 2020;80:388-93.

11. Guan WJ, Ni ZY, Hu Y, et al. Clinical Characteristics of Coronavirus Disease 2019 in China. N Engl J Med 2020;382:1708-20.

12. Wu J, Liu J, Zhao X, et al. Clinical Characteristics of Imported Cases of COVID-19 in Jiangsu Province: A Multicenter Descriptive Study. Clin Infect Dis 2020;71:706-12.

13. Mo P, Xing Y, Xiao Y, et al. Clinical characteristics of refractory COVID-19 pneumonia in Wuhan, China. Clin Infect Dis 2020. [Epub ahead of print].

14. Zhou F, Yu T, Du R, et al. Clinical course and risk factors for mortality of adult inpatients with COVID-19 in Wuhan, China: a retrospective cohort study. Lancet 2020;395:1054-62.

15. Liu K, Chen Y, Lin R, et al. Clinical feature of COVID-19 in elderly patients: a comparison with young and middleaged patients. J Infect 2020;80:e14-8.

16. $\mathrm{Xu} \mathrm{T}$, Chen $\mathrm{C}, \mathrm{Zhu} \mathrm{Z}$, et al. Clinical features and dynamics of viral load in imported and non-imported patients with COVID-19. Int J Infect Dis 2020;94:68-71.

17. Wang Z, Yang B, Li Q, et al. Clinical Features of 69 Cases with Coronavirus Disease 2019 in Wuhan, China. Clin Infect Dis 2020;71:769-77.

18. $\mathrm{Xu} X W, \mathrm{Wu} X X$, Jiang XG, et al. Clinical findings in a group of patients infected with the 2019 novel coronavirus (SARS-Cov-2) outside of Wuhan, China: retrospective case series. BMJ 2020;368:m606.

19. Ruan Q, Yang K, Wang W, et al. Clinical predictors of mortality due to COVID-19 based on an analysis of data of 150 patients from Wuhan, China. Intensive Care Med 2020;46:846-8.

20. Chen J, Qi T, Liu L, et al. Clinical progression of patients with COVID-19 in Shanghai, China. J Infect 2020;80:e1-e6.

21. Rodriguez-Morales AJ, Cardona-Ospina JA, GutiérrezOcampo E, et al. Clinical, laboratory and imaging features of COVID-19: A systematic review and meta-analysis. Travel Med Infect Dis 2020;34:101623. 
22. Fu L, Wang B, Yuan T, et al. Clinical characteristics of coronavirus disease 2019 (COVID-19) in China: A systematic review and meta-analysis. J Infect 2020;80:656-65.

23. Liberati A, Altman DG, Tetzlaff J, et al. The PRISMA statement for reporting systematic reviews and metaanalyses of studies that evaluate healthcare interventions: explanation and elaboration. BMJ 2009;339:b2700.

24. Slim K, Nini E, Forestier D, et al. Methodological index for non-randomized studies (minors): development and validation of a new instrument. ANZ J Surg 2003;73:712-6.

25. Barendregt JJ, Doi SA, Lee YY, et al. Meta-analysis of prevalence. J Epidemiol Community Health 2013;67:974-8.

26. Lin D, Liu L, Zhang M, et al. Co-infections of SARS$\mathrm{CoV}-2$ with multiple common respiratory pathogens in infected patients. Sci China Life Sci 2020;63:606-9.

27. Li Y, Xia L. Coronavirus Disease 2019 (COVID-19): Role of Chest CT in Diagnosis and Management. AJR Am J Roentgenol 2020;214:1280-6.

28. COVID-19, Australia: Epidemiology Report 6 (Reporting week ending 19:00 AEDT 7 March 2020). Commun Dis Intell (2018) 2020;44.

29. Zhou S, Wang Y, Zhu T, et al. CT Features of Coronavirus Disease 2019 (COVID-19) Pneumonia in 62 Patients in Wuhan, China. AJR Am J Roentgenol 2020;214:1287-94.

30. Wang J, Liu J, Wang Y, et al. Dynamic changes of chest CT imaging in patients with corona virus disease-19 (COVID-19). Zhejiang Da Xue Xue Bao Yi Xue Ban 2020;49:191-7.

31. Qin C, Zhou L, Hu Z, et al. Dysregulation of immune response in patients with COVID-19 in Wuhan, China. Clin Infect Dis 2020;71:762-8.

32. Han R, Huang L, Jiang H, et al. Early Clinical and CT Manifestations of Coronavirus Disease 2019 (COVID-19) Pneumonia. AJR Am J Roentgenol 2020;215:338-43.

33. Sun WW, Ling F, Pan JR, et al. Epidemiological characteristics of 2019 novel coronavirus family clustering in Zhejiang Province. Zhonghua Yu Fang Yi Xue Za Zhi 2020;54:E027.

34. Dong XC, Li JM, Bai JY, et al. Epidemiological characteristics of confirmed COVID-19 cases in Tianjin. Zhonghua Liu Xing Bing Xue Za Zhi 2020;41:638-41.

35. Xiao F, Tang M, Zheng X, et al. Evidence for gastrointestinal infection of SARS-CoV-2.
Gastroenterology 2020;158:1831-3.e3.

36. Fan BE, Chong VCL, Chan SSW, et al. Hematologic parameters in patients with COVID-19 infection. Am J Hematol 2020;95:E131-4.

37. Shi Y, Yu X, Zhao H, et al. Host susceptibility to severe COVID-19 and establishment of a host risk score: findings of 487 cases outside Wuhan. Crit Care 2020;24:108.

38. Xu X, Yu C, Qu J, et al. Imaging and clinical features of patients with 2019 novel coronavirus SARS-CoV-2. Eur J Nucl Med Mol Imaging 2020;47:1275-80.

39. He XW, Lai JS, Cheng J, et al. Impact of complicated myocardial injury on the clinical outcome of severe or critically ill COVID-19 patients. Zhonghua Xin Xue Guan Bing Za Zhi 2020;48:456-60.

40. Wu J, Feng CL, Xian XY, et al. Novel coronavirus pneumonia (COVID-19) CT distribution and sign features. honghua Jie $\mathrm{He} \mathrm{He} \mathrm{Hu} \mathrm{Xi}$ Za Zhi 2020;43:321-6.

41. Han H, Yang L, Liu R, et al. Prominent changes in blood coagulation of patients with SARS-CoV-2 infection. Clin Chem Lab Med 2020;58:1116-20.

42. Shi H, Han X, Jiang N, et al. Radiological findings from 81 patients with COVID-19 pneumonia in Wuhan, China: a descriptive study. Lancet Infect Dis 2020;20:425-34.

43. Zhao W, Zhong Z, Xie X, et al. Relation Between Chest CT Findings and Clinical Conditions of Coronavirus Disease (COVID-19) Pneumonia: A Multicenter Study. AJR Am J Roentgenol 2020;214:1072-7.

44. Wu C, Chen X, Cai Y, et al. Risk Factors Associated With Acute Respiratory Distress Syndrome and Death in Patients With Coronavirus Disease 2019 Pneumonia in Wuhan, China. JAMA Intern Med 2020;180:934-43.

45. Bai $\mathrm{P}, \mathrm{He} W$, Zhang XC, et al. Analysis of clinical features of 58 patients with severe or critical 2019 novel coronavirus pneumonia. Zhonghua Ji Zhen Yi Xue Za Zhi 2020:483-7.

46. Wan Q, Shi AQ, He T, et al. Analysis of clinical features of 153 patients with novel coronavirus pneumonia in Chongqing. Zhonghua Lin Chuang Gan Ran Bing Za Zhi 2020:16-20.

47. Liu HF, Zhang DY, Yang Y, et al. Analysis of early chest high resolution CT images of novel coronavirus pneumonia. Zhonghua Fang She Xue Za Zhi 2020:292-5.

48. Ling Y, Lin YX, Qian ZP, et al. Clinical analysis of risk factors for severe patients with novel coronavirus pneumonia. Zhonghua Chuan Ran Bing Za Zhi 
2020:193-8.

49. Zhao Y, Zhong SP, Li F, et al. Clinical characteristics and risk factors of gastrointestinal symptoms in patients with novel coronavirus pneumonia in Xinyang, Henan province. Chinese Journal of Digestion 2020:171-5.

50. Lu XF, Gong W, Wang L, et al. Clinical features and high resolution CT imaging findings of preliminary diagnosis novel coronavirus pneumonia. Zhonghua Fang She Xue Za Zhi 2020:296-9.

51. Li RQ, Tian JG, Yang F, et al. The clinical study on the relationship between serum albumin concentration and lymphocyte levels in patients with 2019-novel coronavirus pneumonia. Zhonghua Ji Zhen Yi Xue Za Zhi 2020:478-82.

52. Hu R, Huang N, Chen W, et al. Comparison of chest CT images between confirmed and suspected cases of COVID-19. Zhonghua Fang She Xue Za Zhi 2020:440-4.

53. Huang L, Han R, Yu PX, et al. A correlation study of CT and clinical features of different clinical types of 2019 novel coronavirus pneumonia. Zhonghua Fang She Xue Za Zhi 2020:300-4.

54. Shi JH, Wang YR, Li WB, et al. Digestive system manifestations and analysis of disease severity in 54 patients with corona virus disease 2019. Chinese Journal of Digestion 2020:167-70.

55. Li Y, Liu T, Liu M, et al. Electrocardiogram abnormalities in patients with COVID-19. Zhonghua Xin Lv Shi Chang Xue Za Zhi 2020:128-32.

56. Cheng JL, Huang C, Zhang GJ, et al. Epidemiological characteristics of novel coronavirus pneumonia in Henan. Zhonghua Jie He He Hu Xi Za Zhi 2020:327-31.

57. Shi YL, Ou JY, Chen X, et al. Expressions of multiple inflammation markers in the patients with 2019 novel coronavirus pneumonia and their clinical values. Zhonghua Jian Yan Yi Xue Za Zhi 2020:346-51.

58. Yu CC, Qu J, Zhang LG, et al. High resolution CT findings and clinical features of novel coronavirus pneumonia in Guangzhou. Zhonghua Fang She Xue Za Zhi 2020:314-7.

59. Li XH, Wang HT, Zhu J, et al. Imaging dynamic observation of COVID-19 patients cured by imported coronavirus pneumonia. Zhonghua Fang She Xue Za Zhi 2020:435-9.

60. Wang SH, Han P, Xiao F, et al. Manifestations of liver injury in 333 hospitalized patients with coronavirus disease 2019. Chinese Journal of Digestion 2020:157-61.

61. Sun DW, Zhang D, Tian RH, et al. Related factors and clinical significance of liver damage in patients with new coronavirus pneumonia. Zhonghua Xiao Hua Wai Ke Za Zhi 2020:360-5.

62. Lv ZB, Guan CS, Yan S, et al. Value of CT findings in predicting transformation of clinical types of COVID-19. Zhonghua Fang She Xue Za Zhi 2020:544-7.

63. Yuan J, Sui YY, Zuo YJ, et al. Analysis of clinical characteristics of 223 patients with new coronavirus pneumonia in Chongqing. Xinan Da Xue Xue Bao 2020;42:17-24.

64. Wang Y, Zhao CC, Gu Y, et al. Analysis of Novel Coronavirus Pneumonia Related Blood Test Indexes in 80 Cases. Journal of Clinical Transfusion and Laboratory Medicine 2020:1-10.

65. Lu YF, Yang ZG, Wang M, et al. Analysis on Chinese medical clinical characteristics of 50 patients with 2019-nCoV-infected pneumonia. Journal of Shanghai University of Traditional Chinese Medicine 2020;34:17-21.

66. Wang XJ, Gao J, Wang XB, et al. Clinical and epidemiological characteristics of patients with COVID-19 in Gansu Province. Chin J Infec Contl 2020;19:223-6.

67. Ding Y, Huang ZF, Zhao SC, et al. Clinical and imaging characteristics of corona virus disease 2019 (COVID-19). Radiol Pract 2020;35:281-5.

68. Dai ZH, Gao LD, Luo KW, et al. Clinical characteristics analysis of novel coronavirus pneumonia in Hunan province. Practical Preventive Medicine 2020;27:396-9.

69. Li JS, Li SY, Xie Y, et al. Clinical characteristics and distribution of TCM syndromes in 524 patients with new coronavirus pneumonia in Henan Province. Journal of Traditional Chinese Medicine 2020:1-6.

70. Lu ZL, He RY, Jiang WY, et al. Clinical characteristics and immune function analysis of COVID-19. Wuhan Da Xue Xue Bao Yi Xue Ban 2020;41:529-32+46.

71. Zhou YP, Zhu CX, Wan XW, et al. Clinical characteristics and laboratory results of 3886 patients with fever and cough. Laboratory Medicine and Clinic 2020:1-9.

72. Zhou SY, Wang CT, Zhang W, et al. Clinical characteristics and treatment effect of 537 cases of novel coronavirus pneumonia in Shandong Province. Shandong Da Xue Xue Bao Yi Xue Ban 2020;58:44-51.

73. Fang XW, Mei Q, Yang TJ, et al. Clinical characteristics and treatment strategies of 79 patients with COVID-19. Chinese Pharmacological Bulletin 2020;36:453-9.

74. Chen $\mathrm{W}, \mathrm{Xu} \mathrm{L}$, Zhang Q, et al. Clinical characteristics of 91 novel coronavirus pneumonia patients in Jingmen 
First People's Hospital. Neimenggu Yi Ke Da Xue Xue Bao 2020;42:117-24.

75. Han J, Dong XF, Hu F, et al. Clinical characteristics of 120 patients infected with SARS-CoV-2. Guangdong Yi Xue 2020;41:772-5.

76. Cheng KB, Wei M, Shen H, et al. Clinical characteristics of 463 patients with common and severe type coronavirus disease. Shanghai Yi Xue 2020:1-15.

77. Xiong J, Jiang WL, Zhou Q, et al. Clinical characteristics, treatment, and prognosis in 89 cases of COVID-2019. Wuhan Da Xue Xue Bao Yi Xue Ban 2020;41:542-6.

78. Xu S, Hu HT, Hu YG, et al. Clinical features of 62 cases of Coronavirus Disease 2019 complicated with acute renal injury. Wuhan Da Xue Xue Bao Yi Xue Ban 2020;41:537-41.

79. Xiao KH, Shui LL, Pang XH, et al. The clinical features of the 143 patients with COVID-19 in North-East of Chongqing. Acta Academiae Medicinae Militaris Tertiae 2020:1-5.

80. Chen ZY, Cheng ZY, Zhang XH, et al. Clinical manifestations and $\mathrm{CT}$ characteristics of corona virus disease 2019 (COVID-19). Radiologic Practice 2020;35:286-90.

81. Chang ZY, Yang WB, Wang Q, et al. Clinical significance of serum hs-CRP, IL-6, and PCT in diagnosis and prognosis of patients with COVID-19. Drugs \& Clinic 2020;35:417-20.

82. Hou KK, Zhang N, Li T, et al. CT features of corona virus disease 2019 (COVID-19) in diferent stages and its corelation with neutrophil-lymphocyte ratio (NLR) and T lymphocyte subsets. Radiologic Practice 2020;35:272-6.

83. Zhong Q, LI Z, Shen HY, et al. CT imaging features of patients with different clinical types of coronavirus disease 2019 (COVID-19). Zhejiang Da Xue Xue Bao Yi Xue Ban 2020;49:198-202.

84. Qian ZC, Song XY, Li SS, et al. Epidemiological and clinical characteristics analysis of severe and critical corona virus disease 2019. Wuhan Da Xue Xue Bao Yi Xue Ban 2020;41:533-6.

85. Yang K, Ren MH, Xiao LY, et al. Epidemiological and clinical characteristics of 57 cases of new coronavirus pneumonia in non-epidemic areas. Acta Academiae Medicinae Militaris Tertiae 2020:1-5.

86. Wang AH, Long Q, Tian C. Initial symptoms and epidemiological characteristics of confirmed cases of novel coronavirus pneumonia (COVID-19) in the west of Chongqing. Chin J Infec Contl 2020;19:234-8.
87. Ma PQ, Yuan YS, Zhang L, et al. Manifestations of the initial chest $\mathrm{CT}$ and its association with laboratory tests in 75 COVID-19 patients. International Journal of Medical Radiology 2020;43:127-30.

88. Sui HY, Bi YF, Zhu ZG, et al. A preliminary study on the characteristics of TCM syndromes of 88 patients with new coronavirus pneumonia in Tianjin. Journal of Traditional Chinese Medicine 2020;61:837-41.

89. Fang L, Zhu QG, Cheng W, et al. Retrospective analysis on 308 cases of COVID-19 and clinical application program of Kangyi Qiangshen Gong exercise prescription. Shanghai Journal of Traditional Chinese Medicine 2020;54:40-5.

90. Chen X, Tong J, Xiang JH, et al. Retrospective study on the epidemiological characteristics of 139 patients with novel coronavirus pneumonia on the effects of Severity. Chongqing Yi Xue 2020:1-9.

91. Ran J, Li YP, L iQT, et al. Study of TCM Syndrome in 209 Novel Coronavirus Pneumonia Cases of Chongqing in 2020. J Emerg Tradit Chin Med 2020;29:753-5+8.

92. Yu SM, Cui YF, Wang ZX, et al. Traditional Chinese medicine syndrome analysis with COVID-19 on admission. World Chinese Medicine 2020;15:494-6+501.

93. Liang W, Guan W, Chen R, et al. Cancer patients in SARS-CoV-2 infection: a nationwide analysis in China. Lancet Oncol 2020;21:335-7.

94. Wang D, Hu B, Hu C, et al. Clinical Characteristics of 138 Hospitalized Patients With 2019 Novel Coronavirus-Infected Pneumonia in Wuhan, China. Jama 2020;323:1061-9.

95. Zhang JJ, Dong X, Cao YY, et al. Clinical characteristics of 140 patients infected with SARS-CoV-2 in Wuhan, China. Allergy 2020;75:1730-41.

96. Liu K, Fang YY, Deng Y, et al. Clinical characteristics of novel coronavirus cases in tertiary hospitals in Hubei Province. Chin Med J (Engl) 2020;133:1025-31.

97. Yang X, Yu Y, Xu J, et al. Clinical course and outcomes of critically ill patients with SARS-CoV-2 pneumonia in Wuhan, China: a single-centered, retrospective, observational study. Lancet Respir Med 2020;8:475-81.

98. Chen N, Zhou M, Dong X, et al. Epidemiological and clinical characteristics of 99 cases of 2019 novel coronavirus pneumonia in Wuhan, China: a descriptive study. Lancet 2020;395:507-13.

99. Pan Y, Guan H, Zhou S, et al. Initial CT findings and temporal changes in patients with the novel coronavirus pneumonia (2019-nCoV): a study of 63 patients in Wuhan, China. Eur Radiol 2020;30:3306-9. 
100. The latest situation of the new coronavirus pneumonia epidemic situation as of 24:00 on March 30. Available online: http://www.nhc.gov.cn/xcs/yqtb/202003/ec2689b0 e716468fbfff7cf890c74bb7.shtml. Accessed 03/31 2020.

101.Zheng Z, Peng F, Xu B, et al. Risk factors of critical \& mortal COVID-19 cases: A systematic literature review and meta-analysis. J Infect 2020;81:e16-e25.

102. Gal-Oz ST, Maier B, Yoshida H, et al. ImmGen report: sexual dimorphism in the immune system transcriptome. Nat Commun 2019;10:4295.

103. Arnold AP, Cassis LA, Eghbali M, et al. Sex Hormones and Sex Chromosomes Cause Sex Differences in the Development of Cardiovascular Diseases. Arterioscler Thromb Vasc Biol 2017;37:746-56.

104. Yang J, Zheng Y, Gou X, et al. Prevalence of comorbidities and its effects in patients infected with SARS-CoV-2: a systematic review and meta-analysis. Int J Infect Dis 2020;94:91-5.

Cite this article as: Xie J, Wang Q, Xu Y, Zhang T, Chen L, Zuo X, Liu J, Huang L, Zhan P, Lv T, Song Y. Clinical characteristics, laboratory abnormalities and CT findings of COVID-19 patients and risk factors of severe disease: a systematic review and meta-analysis. Ann Palliat Med 2021;10(2):1928-1949. doi: 10.21037/apm-20-1863
105. Terpos E, Ntanasis-Stathopoulos I, Elalamy I, et al. Hematological findings and complications of COVID-19. Am J Hematol 2020;95:834-47.

106. Henry BM, de Oliveira MHS, Benoit S, et al. Hematologic, biochemical and immune biomarker abnormalities associated with severe illness and mortality in coronavirus disease 2019 (COVID-19): a meta-analysis. Clin Chem Lab Med 2020;58:1021-8.

107.Koo HJ, Lim S, Choe J, et al. Radiographic and CT Features of Viral Pneumonia. Radiographics 2018;38:719-39.

108. Chung M, Bernheim A, Mei X, et al. CT Imaging Features of 2019 Novel Coronavirus (2019-nCoV). Radiology 2020;295:202-7.

109. Bernheim A, Mei X, Huang M, et al. Chest CT Findings in Coronavirus Disease-19 (COVID-19): Relationship to Duration of Infection. Radiology 2020;295:200463. 
Table S1 Bias risk assessment

\begin{tabular}{|c|c|c|c|c|c|c|c|c|c|}
\hline Study & (1) & (2) & (3) & (4) & (5) & (6) & (7) & (8) & Score \\
\hline Liu W & 2 & 2 & 2 & 2 & 2 & 1 & 1 & 0 & 12 \\
\hline Chen C & 2 & 2 & 2 & 2 & 2 & 0 & 0 & 0 & 10 \\
\hline Tian S & 2 & 2 & 2 & 2 & 2 & 1 & 2 & 0 & 13 \\
\hline LiK & 2 & 2 & 2 & 2 & 2 & 0 & 0 & 0 & 10 \\
\hline Xu YH & 2 & 1 & 2 & 2 & 2 & 1 & 2 & 0 & 12 \\
\hline Yang W & 2 & 2 & 2 & 2 & 2 & 1 & 2 & 0 & 13 \\
\hline Guan WJ & 2 & 2 & 2 & 2 & 2 & 2 & 2 & 0 & 14 \\
\hline Wu J & 2 & 2 & 2 & 2 & 2 & 1 & 2 & 0 & 13 \\
\hline Mo P & 2 & 2 & 2 & 2 & 2 & 1 & 2 & 0 & 13 \\
\hline Zhou F & 2 & 2 & 2 & 2 & 2 & 2 & 2 & 0 & 14 \\
\hline Liu K & 2 & 2 & 2 & 2 & 2 & 1 & 2 & 0 & 13 \\
\hline Xu T & 2 & 2 & 2 & 2 & 2 & 1 & 2 & 0 & 13 \\
\hline Wang Z & 2 & 2 & 2 & 2 & 2 & 1 & 2 & 0 & 13 \\
\hline Xu XW & 2 & 2 & 2 & 2 & 2 & 1 & 2 & 0 & 13 \\
\hline Ruan Q & 2 & 1 & 2 & 2 & 2 & 0 & 0 & 0 & 9 \\
\hline Chen J & 2 & 2 & 2 & 2 & 2 & 1 & 2 & 0 & 13 \\
\hline Lin D & 2 & 2 & 2 & 2 & 2 & 0 & 0 & 0 & 10 \\
\hline $\mathrm{LiY}$ & 2 & 2 & 2 & 2 & 2 & 0 & 0 & 0 & 10 \\
\hline $\begin{array}{l}\text { COVID-19 } \\
\text { team } \\
\text { Australia }\end{array}$ & 2 & 2 & 2 & 2 & 2 & 0 & 0 & 0 & 10 \\
\hline Zhou S & 2 & 2 & 2 & 2 & 2 & 0 & 0 & 0 & 10 \\
\hline Wang J & 2 & 2 & 2 & 2 & 2 & 0 & 0 & 0 & 10 \\
\hline Qin C & 2 & 2 & 2 & 2 & 2 & 0 & 0 & 0 & 10 \\
\hline Han R & 2 & 2 & 2 & 2 & 2 & 0 & 0 & 0 & 10 \\
\hline Sun WW & 2 & 1 & 2 & 2 & 2 & 0 & 0 & 0 & 9 \\
\hline Dong XC & 2 & 1 & 2 & 2 & 2 & 0 & 0 & 0 & 9 \\
\hline Xiao F & 2 & 2 & 2 & 2 & 2 & 0 & 0 & 0 & 10 \\
\hline Fan BE & 2 & 2 & 2 & 2 & 2 & 0 & 0 & 0 & 10 \\
\hline Shi Y & 2 & 1 & 2 & 2 & 2 & 1 & 2 & 0 & 12 \\
\hline XuX & 2 & 2 & 2 & 2 & 2 & 1 & 2 & 0 & 13 \\
\hline $\mathrm{He} X W$ & 2 & 2 & 2 & 2 & 2 & 0 & 0 & 0 & 10 \\
\hline Wu J & 2 & 1 & 2 & 2 & 2 & 0 & 0 & 0 & 9 \\
\hline $\mathrm{Han} \mathrm{H}$ & 2 & 2 & 2 & 2 & 2 & 0 & 0 & 0 & 10 \\
\hline Shi H & 2 & 2 & 2 & 2 & 2 & 1 & 2 & 0 & 13 \\
\hline Zhao W & 2 & 1 & 2 & 2 & 2 & 0 & 0 & 0 & 9 \\
\hline
\end{tabular}

Table S1 (continued)
Table S1 (continued)

\begin{tabular}{|c|c|c|c|c|c|c|c|c|c|}
\hline Study & (1) & (2) & (3) & (4) & (5) & (6) & (7) & (8) & Score \\
\hline Wu C & 2 & 2 & 2 & 2 & 2 & 1 & 2 & 0 & 13 \\
\hline Wang SH & 2 & 2 & 2 & 2 & 2 & 0 & 0 & 0 & 10 \\
\hline Shi JH & 2 & 2 & 2 & 2 & 2 & 1 & 2 & 0 & 13 \\
\hline Zhao Y & 2 & 2 & 2 & 2 & 2 & 0 & 0 & 0 & 10 \\
\hline Ling $Y$ & 2 & 2 & 2 & 2 & 2 & 0 & 0 & 0 & 10 \\
\hline Cheng JL & 2 & 2 & 2 & 2 & 2 & 0 & 0 & 0 & 10 \\
\hline Huang L & 2 & 2 & 2 & 2 & 2 & 0 & 0 & 0 & 10 \\
\hline Lu XF & 2 & 2 & 2 & 2 & 2 & 0 & 0 & 0 & 10 \\
\hline Liu HF & 2 & 2 & 2 & 2 & 2 & 0 & 0 & 0 & 10 \\
\hline Yu CC & 2 & 2 & 2 & 2 & 2 & 0 & 0 & 0 & 10 \\
\hline Li XH & 2 & 2 & 2 & 2 & 2 & 1 & 1 & 0 & 12 \\
\hline Hu R & 2 & 2 & 2 & 2 & 2 & 1 & 1 & 0 & 12 \\
\hline Lu ZB & 2 & 2 & 2 & 2 & 2 & 1 & 2 & 0 & 13 \\
\hline LiY & 2 & 2 & 2 & 2 & 2 & 0 & 0 & 0 & 10 \\
\hline Shi YL & 2 & 2 & 2 & 2 & 2 & 0 & 0 & 0 & 10 \\
\hline Li RQ & 2 & 2 & 2 & 2 & 2 & 0 & 0 & 0 & 10 \\
\hline Bai P & 2 & 2 & 2 & 2 & 2 & 1 & 2 & 0 & 13 \\
\hline Sun DW & 2 & 2 & 2 & 2 & 2 & 0 & 0 & 0 & 10 \\
\hline Wan Q & 2 & 2 & 2 & 2 & 2 & 1 & 2 & 0 & 13 \\
\hline Lu YF & 2 & 1 & 2 & 2 & 2 & 0 & 0 & 0 & 9 \\
\hline Yu SM & 2 & 2 & 2 & 2 & 2 & 0 & 0 & 0 & 10 \\
\hline Yang K & 2 & 2 & 2 & 2 & 2 & 1 & 2 & 0 & 13 \\
\hline XuS & 2 & 2 & 2 & 2 & 2 & 1 & 2 & 0 & 13 \\
\hline $\mathrm{Ma} P Q$ & 2 & 2 & 2 & 2 & 2 & 0 & 0 & 0 & 10 \\
\hline Zhao CC & 2 & 2 & 2 & 2 & 2 & 0 & 0 & 0 & 10 \\
\hline Chen X & 2 & 2 & 2 & 2 & 2 & 0 & 0 & 0 & 10 \\
\hline Fang L & 2 & 2 & 2 & 2 & 2 & 0 & 0 & 0 & 10 \\
\hline Fang XW & 2 & 2 & 2 & 2 & 2 & 1 & 2 & 0 & 13 \\
\hline Zhong Q & 2 & 2 & 2 & 2 & 2 & 0 & 0 & 0 & 10 \\
\hline Ran J & 2 & 2 & 2 & 2 & 2 & 0 & 0 & 0 & 10 \\
\hline Yuan J & 2 & 2 & 2 & 2 & 2 & 1 & 2 & 0 & 13 \\
\hline Xiao KH & 2 & 2 & 2 & 2 & 2 & 1 & 2 & 0 & 13 \\
\hline Wang AH & 2 & 2 & 2 & 2 & 2 & 0 & 0 & 0 & 10 \\
\hline Wang XJ & 2 & 2 & 2 & 2 & 2 & 0 & 0 & 0 & 10 \\
\hline Li JS & 2 & 2 & 2 & 2 & 2 & 0 & 0 & 0 & 10 \\
\hline
\end{tabular}

Table S1 (continued)
Table S1 (continued)

\begin{tabular}{|c|c|c|c|c|c|c|c|c|c|}
\hline Study & (1) & (2) & (3) & (4) & (5) & (6) & (7) & (8) & Score \\
\hline Han J & 2 & 2 & 2 & 2 & 2 & 0 & 0 & 0 & 10 \\
\hline Dai ZH & 2 & 2 & 2 & 2 & 2 & 0 & 0 & 0 & 10 \\
\hline Chen W & 2 & 2 & 2 & 2 & 2 & 0 & 0 & 0 & 10 \\
\hline Cheng KB & 2 & 2 & 2 & 2 & 2 & 1 & 2 & 0 & 13 \\
\hline $\begin{array}{l}\text { COVID-19 } \\
\text { team } \\
\text { Shandong }\end{array}$ & 2 & 2 & 2 & 2 & 2 & 0 & 0 & 0 & 10 \\
\hline Sui HY & 2 & 2 & 2 & 2 & 2 & 0 & 0 & 0 & 10 \\
\hline Zhou YP & 2 & 2 & 2 & 2 & 2 & 0 & 0 & 0 & 10 \\
\hline Ding $Y$ & 2 & 2 & 2 & 2 & 2 & 0 & 0 & 0 & 10 \\
\hline Xiong $\mathrm{J}$ & 2 & 2 & 2 & 2 & 2 & 1 & 2 & 0 & 13 \\
\hline Hou KK & 2 & 2 & 2 & 2 & 2 & 1 & 2 & 0 & 13 \\
\hline Chen ZY & 2 & 2 & 2 & 2 & 2 & 0 & 0 & 0 & 10 \\
\hline Chang ZY & 2 & 2 & 2 & 2 & 2 & 0 & 0 & 0 & 10 \\
\hline Qian ZC & 2 & 2 & 2 & 2 & 2 & 1 & 2 & 0 & 13 \\
\hline Lu ZL & 2 & 2 & 2 & 2 & 2 & 0 & 0 & 0 & 10 \\
\hline Chen NS & 2 & 2 & 2 & 2 & 2 & 2 & 2 & 0 & 14 \\
\hline Liang W & 2 & 2 & 2 & 2 & 2 & 1 & 2 & 0 & 13 \\
\hline Yang XB & 2 & 2 & 2 & 2 & 2 & 2 & 2 & 0 & 14 \\
\hline Wang DW & 2 & 2 & 2 & 2 & 2 & 2 & 2 & 0 & 14 \\
\hline Liu K & 2 & 2 & 2 & 2 & 2 & 1 & 2 & 0 & 13 \\
\hline Pan YY & 2 & 2 & 2 & 2 & 2 & 0 & 0 & 0 & 10 \\
\hline Zhang JJ & 2 & 2 & 2 & 2 & 2 & 1 & 2 & 0 & 13 \\
\hline
\end{tabular}

(1) A clearly stated aim; (2) Inclusion of consecutive patients; (3) Prospective collection of data; (4) Endpoints appropriate to the aim of the study; (5) Unbiased assessment of the study endpoint; (6) Follow-up period appropriate to the aim of the study; (7) Loss to follow-up less than 5\%; (8) Prospective calculation of the study size. The items are scored 0 (not reported), 1 (reported but inadequate), or 2 (reported and adequate). The global ideal score being 16 for non-comparative studies. 


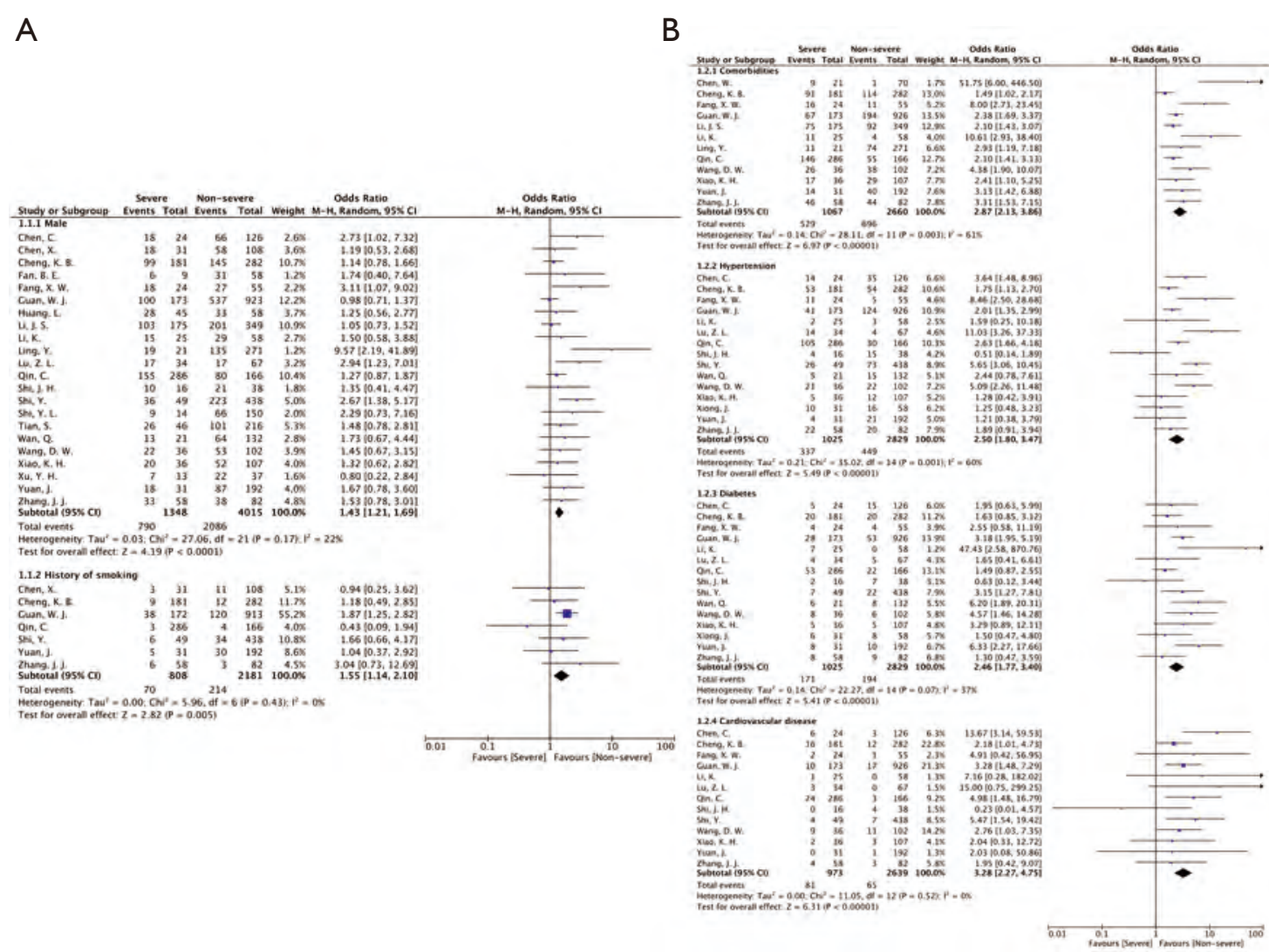

C

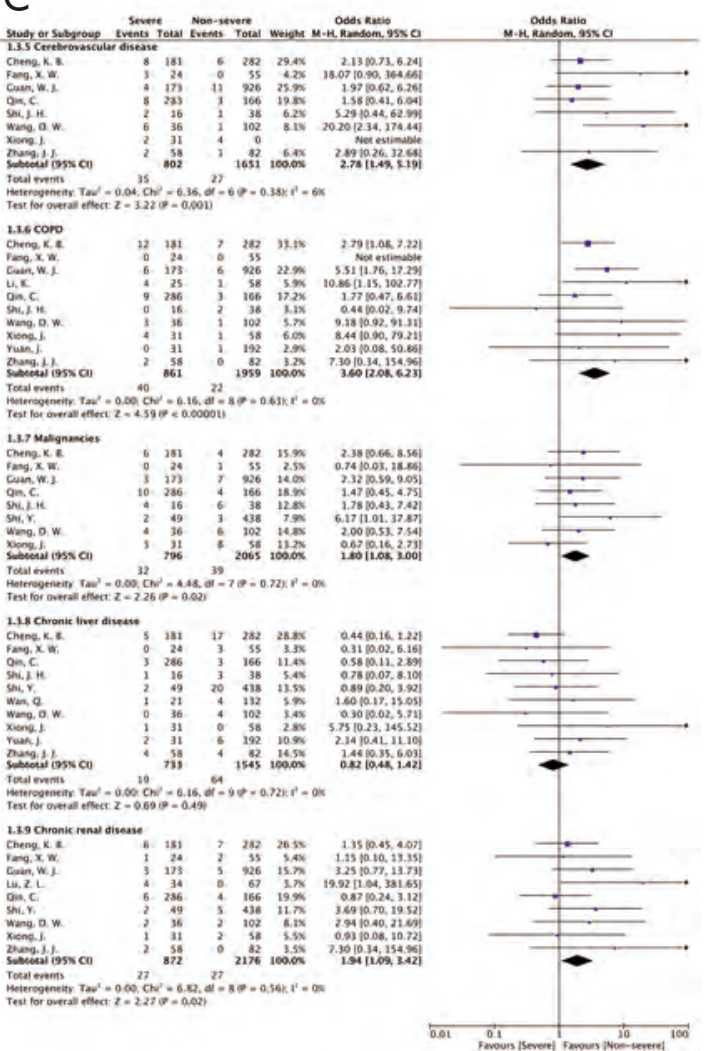

Figure S1 Meta-analysis of male, history of smoking, and comorbidities according to COVID-19 severity. COPD, chronic obstructive pulmonary disease. 
A

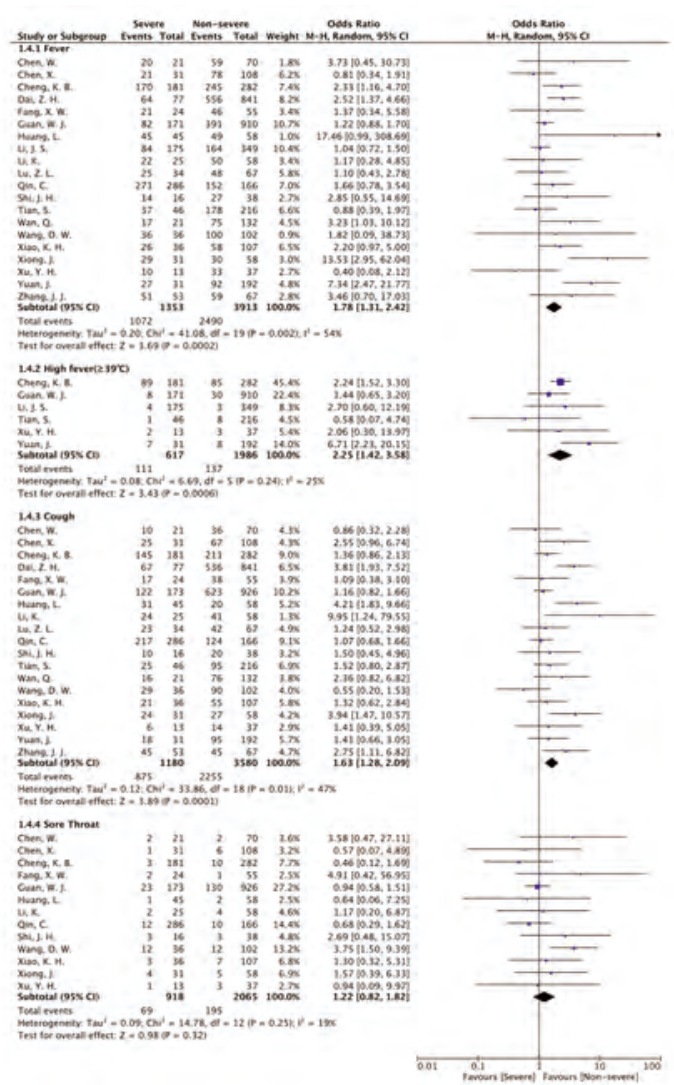

B

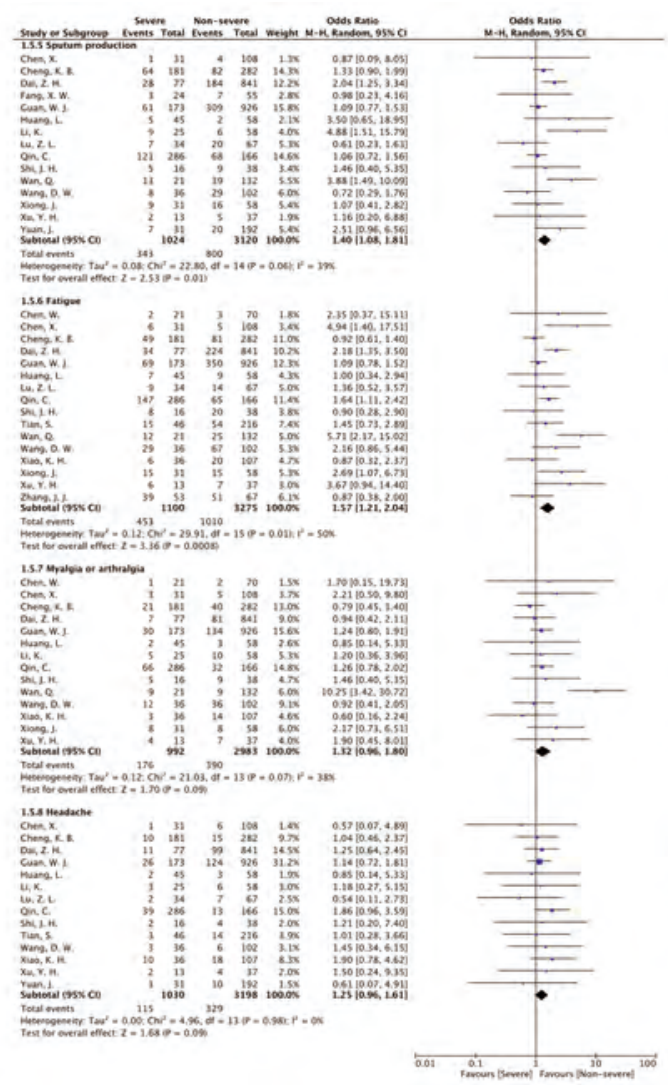

C

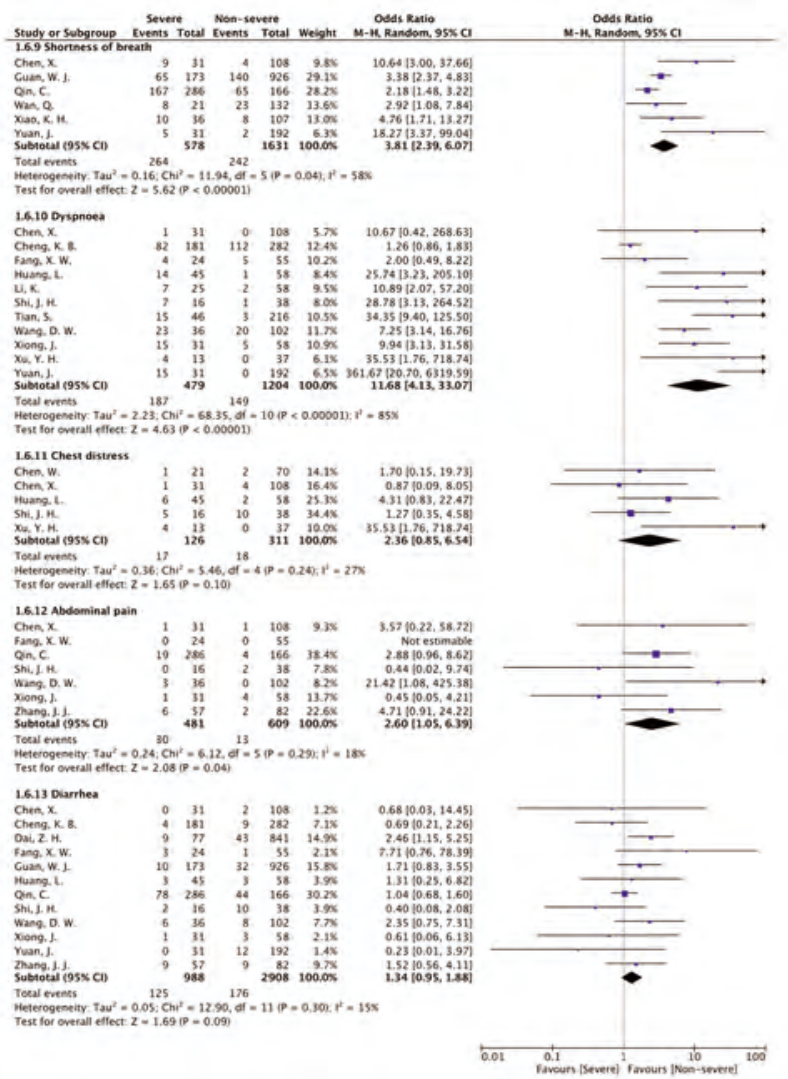

Figure S2 Meta-analysis of clinical symptoms according to COVID-19 severity. 
A

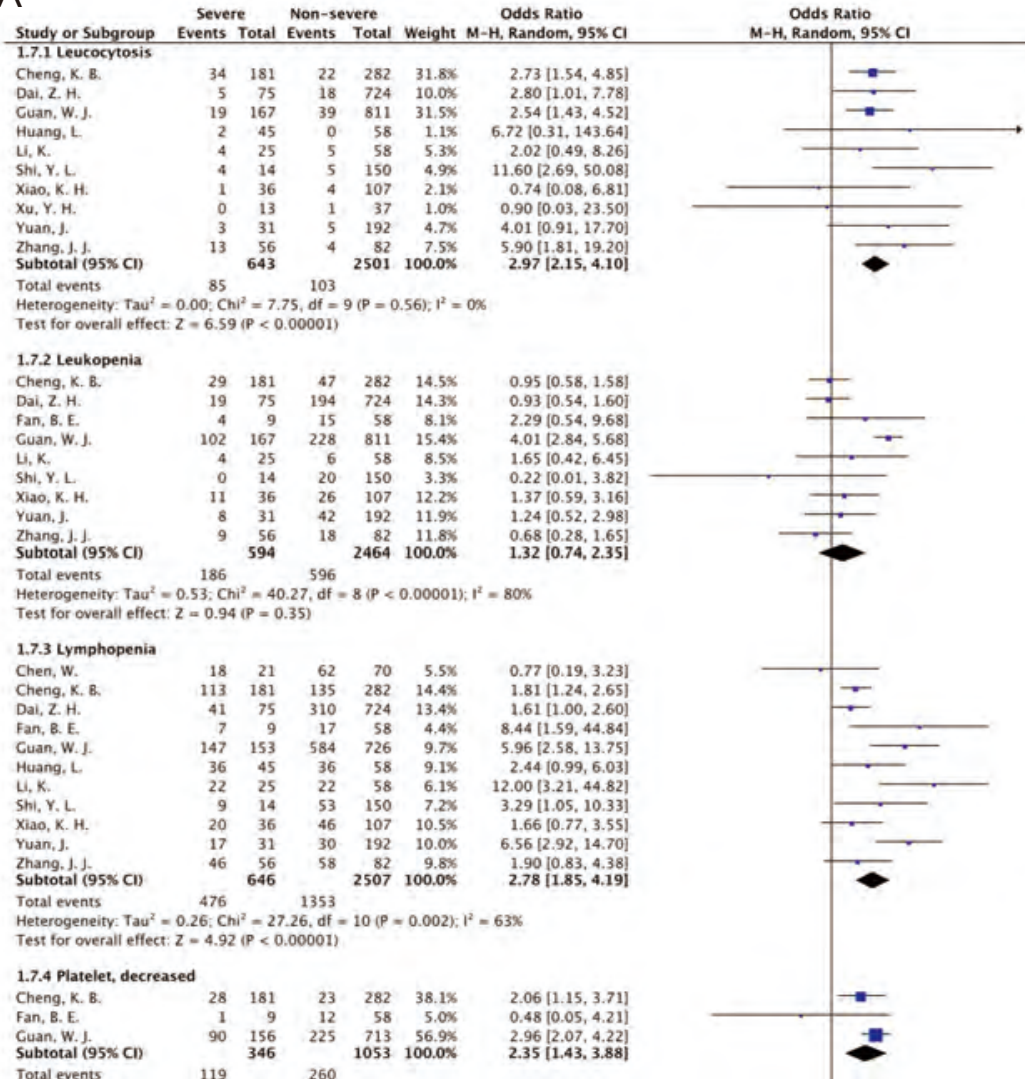

B

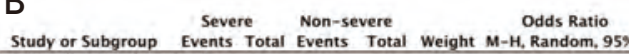
$\begin{array}{lrrrrrr}\text { 1.8.7 Albumin, decreased } & & & & & & \\ \text { Cheng, K. B. } & 65 & 181 & 60 & 282 & 59.6 \% & 2.07[1.37,3.14] \\ \text { Yvan,J. } & 18 & 31 & 45 & 192 & 40.4 \% & 4.52[2.06,9.944 \\ \text { Subtotal (95\% CI) } & & 212 & & 474 & 100.0 \% & 2.84(1.34,6.02]\end{array}$

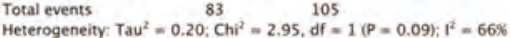
Heterogeneity $\mathrm{Tau}^{2}=0.20$ Chi $^{2}=2.95$,

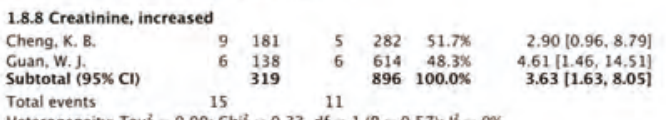
Heterogeneity Tau $^{2}=0.00 ;$ Ch $^{2}=0.33$, df $=1(P=0.57): 1^{2}=0.0$ Test for overall effect: $Z=3.17(P=0.002)$

1.8 .9 Creatine kinase, increased

$\begin{array}{llllllll}\text { Cheng, K. B. } & 17 & 181 & 12 & 277 & 29.06 & 2.29[1.07,4.921\end{array}$ $\begin{array}{llllllll}\text { Guan, W. J. } & 23 & 121 & 67 & 536 & 41.2 \% & 1.64[0.98,2.77]\end{array}$ $\begin{array}{lrrrrrr}\text { Yuan, J. } & 11 & 31 & 19 & 192 & 24.7 \% & 5.01[2.09 .12 .01] \\ \text { Zhang.J.J. } & 3 & 25 & 1 & 35 & 5.2 \% & 4.64[0.45 .47 .45]\end{array}$ $2.51[1.45,4.37$ Heterogeneity. $\mathrm{Tau}^{2}=0.12 ; \mathrm{Ch}^{2}=4.99$, df $=3(\mathrm{P}=0.17): \mathrm{I}^{2}=40 \mathrm{x}$ Test for overall effect: $Z=3.27(p=0.001)$

1.8.10 LDH, increased

\begin{tabular}{llllllll} 
Cheng, K. B. & 128 & 181 & 132 & 277 & $26.6 \%$ & $2.65[1.78,3.95]$ \\
\hline & & 4 & 19 & 25 & 551 & $26.6 \%$ & $2.34[1.57,3.47]$
\end{tabular} $\begin{array}{lllllll}\text { Fan, B. E. } & 4 & 9 & 5 & 58 & 9.5 \% & 8.48(1.71,42.13\end{array}$ $\begin{array}{lllllll}\text { Cuan, W. J. } & 72 & 124 & 205 & 551 & 26.6 \% & 2.34[1.57,3.47\end{array}$

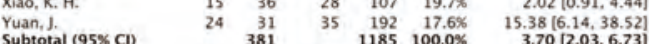
2430.405 Teterogeneity Tau $^{2}=0.31: \mathrm{Chi}^{2}=16.55$,

1.8.11 CRP, increased

$\begin{array}{lllllll}\text { Cheng, K. B. } & 142 & 181 & 170 & 282 & 32.7 \% & 2.40[1.56,3.68] \\ \text { Guan, W. J. } & 110 & 135 & 371 & 658 & 31.0 \% & 3.40[2.15,5.40]\end{array}$ $\begin{array}{llllll}23 & 25 & 27 & 58 & 6.5 \% & 13.20[2.85,61.2\end{array}$

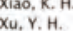

Shang, f. J. Total events

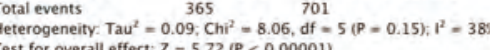
$\begin{aligned} & 1.8 .12 \mathrm{PCT} \text {, increased } \\ & \text { Fang. X.W. }\end{aligned} \quad 1 \quad 24 \quad 0 \quad 55 \quad 1.7 \% \quad 7.09[0.28,180.32]$

Odds Ratio $\mathrm{M}-\mathrm{H}, \mathrm{Random}, 95$

Figure S3 Meta-analysis of laboratory abnormalities according to COVID-19 severity. ALT, alanine aminotransferase; AST, aspartate aminotransferase; LDH, lactic dehydrogenase; CRP, C-reactive protein; PCT, procalcitonin. 


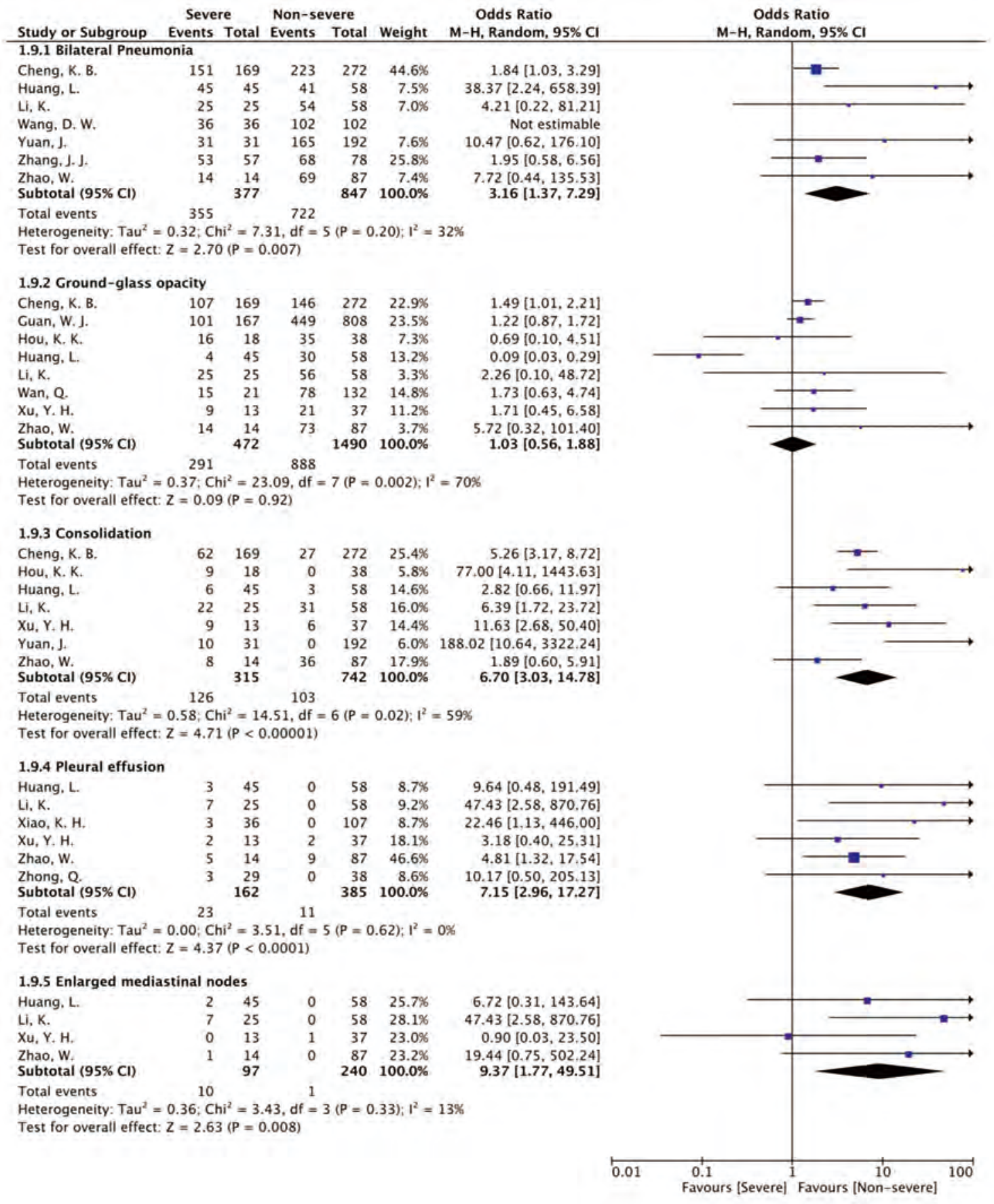

Figure S4 Meta-analysis of CT findings according to COVID-19 severity. 